\title{
ARQUEOLOGÍA DE LA PUNTA SANTA ANA: RECONSTRUCCIÓN DE SECUENCIAS DE OCUPACIÓN DE CAZADORES-RECOLECTORES MARINOS DEL ESTRECHO DE MAGALLANES, PATAGONIA AUSTRAL, CHILE ${ }^{1}$
}

\author{
FLAVIA MORELLO", JIMENA TORRES", ISMAEL MARTÍNEZ ${ }^{* * *}$, KARINA RODRIGUEZ, MANUEL \\ ARROYO-KALIN ${ }^{\ldots * *}$, CHARLES FRENCH $^{*+\cdots *}$, VICTOR SIERPE* Y MANUEL SAN ROMÁN
}

\section{RESUMEN}

Presentamos los resultados obtenidos durante una investigación orientada a la identificación de yacimientos y análisis de sus evidencias para reconstruir secuencias de ocupación de cazadores-recolectores marinos en diferentes puntos específicos de Patagonia Meridional. En este trabajo abordamos la caracterización de tres yacimientos arqueológicos de la localidad de Punta Santa Ana, estrecho de Magallanes. Los conjuntos estudiados corresponden a campamentos emplazados a distinta elevación sobre el nivel del mar actual, con antigüedades de 6300, 2700 y 700 años AP (no calibrados). Estos conjuntos habrían sido originados en lapsos cortos de tiempo y presentan una serie de características que sugieren discontinuidad en cuanto las tradiciones tecnológicas y estrategias de subsistencia a lo largo del tiempo.

PALABRAS CLAVE: cazadores-recolectores, adaptación marina, secuencia temporal, estrecho de Magallanes, Patagonia.

\section{PUNTA SANTA ANA ARCHAEOLOGY: RECONSTRUCTION OF MARINE HUNTER-GATHERER OCCUPATION SEQUENCES FROM THE MAGELLAN STRAIT, SOUTHERNMOST PATAGONIA, CHILE}

\footnotetext{
ABSTRACT

We present results of research focused on the identification of sites and the analysis of their archaeological evidence in order to reconstruct occupation sequences of marine hunter-gatherer groups at specific localities of Southernmost Patagonia. In this paper we address the characterization of three archaeological sites at Punta Santa Ana area, Strait of Magellan. The studied assemblages are from camp-sites located at

1 Proyecto FONDECYT 1085329 y CD HACS "Identidad del Fin del Mundo: Patagonia, Tierra del Fuego y Antártica". Centro de Estudios del Hombre Austral del Instituto de la Patagonia, Universidad de Magallanes. Av. Bulnes 01890, Punta Arenas, Chile. flavia.morello@umag.cl; msanromanbontes@gmail.com; ka_ri_na_yo@hotmail.com; victor_sierpe@yahoo. com.

* UMR 7041 - CNRS (Francia). jimena.torres@malix.univ-paris1.fr.

**a Arqueólogo, ismart68@gmail.com.

***** Institute of Archaeology, University College London. m.arroyo-kalin@ucl.ac.uk.

***** Division of Archaeology, Department of Archaeology and Anthropology, University of Cambridge, Inglaterra. caif2@cam. ac.uk.
} 
different elevations above current sea level, with dates of 6300, 2700 and 700 years BP (not calibrated). These assemblages have been formed in short time periods and have a number of features that suggest discontinuity in technological traditions and subsistence strategies over time.

KEY WORDS: hunter-gatherers, marine adaptations, archaeological sequence, Magellan Strait, Patagonia.

\section{INTRODUCCIÓN}

Los estudios realizados en los últimos años en el marco del proyecto FONDECYT 1085329 Secuencias de ocupación de cazadores-recolectores marinos en Patagonia austral: descifrando trayectorias tecnológicas y cinegéticas durante los últimos 6000 años, nos han permitido obtener resultados importantes en la identificación de yacimientos y evidencias arqueológicas. Los que nos ayudan a llenar importantes vacíos en los conocimientos sobre los grupos de cazadores recolectores marinos de la Patagonia meridional, así como también de su distribución temporal y espacial. Estas investigaciones han sido motivadas por la necesidad de discutir interpretaciones previas que sugerían continuidades regionales en las tradiciones tecnológicas y estrategias de subsistencia a lo largo del Holoceno (Legoupil 1997). Estas continuidades se basaban en semejanzas detectadas entre sitios adscritos a grupos de cazadores-recolectores marinos en los extremos del lapso temporal en que este tipo de adaptaciones han sido descritas, es decir, entre circa 6500 años AP y las postrimerías del siglo XIX.

Debido a que una de las características del registro arqueológico de adaptaciones costeras en el estrecho de Magallanes y sectores aledaños (mar de Otway y Skyring) es la ausencia de superposición de ocupaciones cronológicamente distanciadas en un mismo locus espacial (sitio arqueológico), nos vimos enfrentados a un primer desafío: ubicar registros que abarcasen los últimos 6500 años radiocarbónicos de manera más o menos continua en una localidad puntual. Ello con miras a establecer una base de datos que nos permitiera reconstruir una secuencia de ocupaciones de carácter local. Este primer acometido resultaba clave para avanzar en la caracterización de tecnologías y estrategias de subsistencia descritas para grupos de cazadores-recolectores marinos durante diferentes momentos del Holoceno.
Basándonos en criterios geomorfológicos, desarrollamos prospecciones arqueológicas en las inmediaciones del sitio Punta Santa Ana 1, descubierto y excavado en la década de 1970 por Ortiz-Troncoso $(1975,1979)$ y datado hacia el 6.500 AP. La búsqueda, que contempló el muestreo de diferentes geoformas, detectó sitios arqueológicos sobre distintas terrazas marinas, situación que evidenció una cronología decreciente en relación a su elevación con respecto al nivel del mar actual (San Román et al. 2009). En un trabajo previo (op. cit.) explicamos que este hecho se ajustaba a dos principios: primero, que los campamentos de cazadores marinos se instalaban muy próximos a la costa (Ortiz-Troncoso 1975:99); segundo que la serie de terrazas marinas de esta zona de Patagonia registra tanto el máximo transgresivo durante Holoceno medio y el posterior descenso del nivel del mar, así como procesos locales de rebote isostático debido al derretimiento de las masas glaciares de la última glaciación pleistocena (Porter et al.1984; McCulloch y Davies 2001).

A partir de excavaciones extensivas en los yacimientos Punta Santa Ana 2 (PSA-2) y Punta Santa Ana 3 (PSA-3), del estudio de colecciones y antecedentes del sitio Punta Santa Ana 1 (PSA-1), excavado previamente (Ortiz-Troncoso 1975), y del estudio geoarqueológico de los sedimentos de este último sitio, hemos avanzado en una primera caracterización de la secuencia de ocupación en esta localidad del estrecho de Magallanes. A continuación, presentamos los principales resultados de nuestras investigaciones y los alcances y perspectivas que éstos plantean en la interpretación de las trayectorias descritas por los grupos de cazadores-recolectores marinos que habitaron la Punta Santa Ana durante buena parte del Holoceno. 


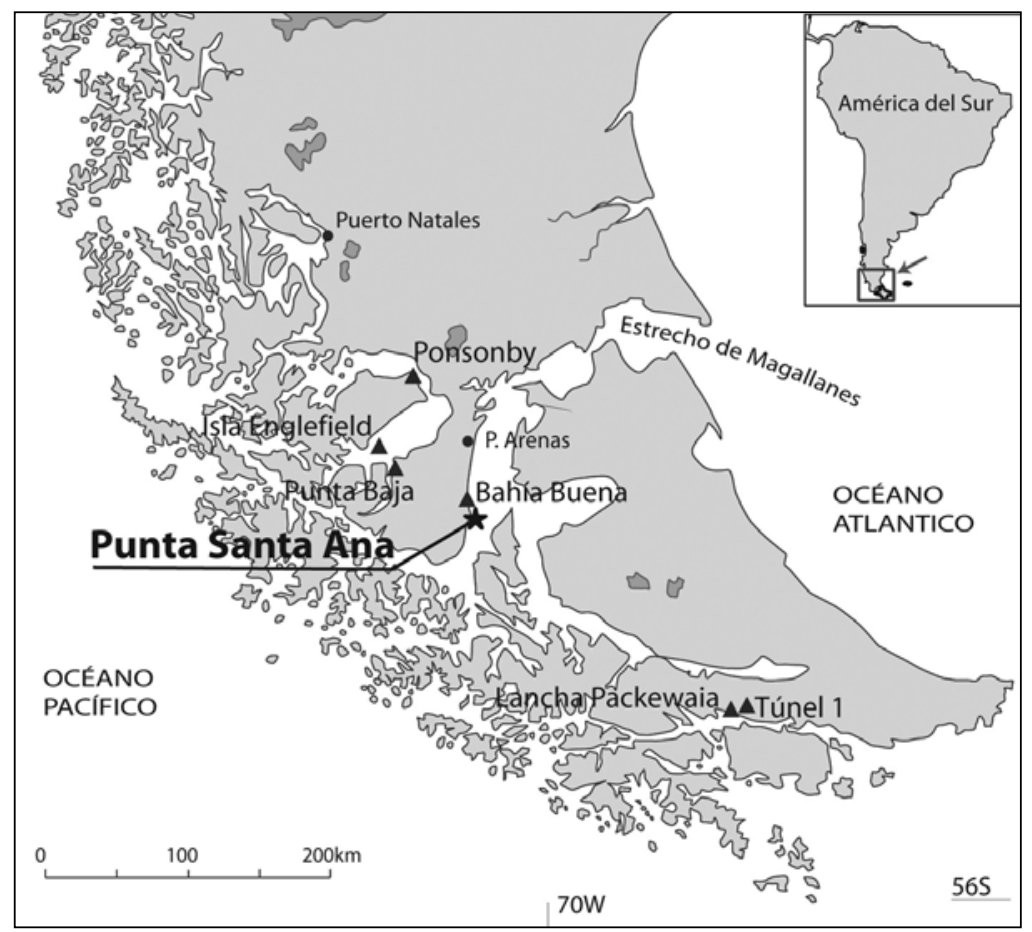

Fig. 1. Ubicación de Punta Santa Ana y otros sitios arqueológicos de ocupaciones de cazadores marinos de Patagonia austral.

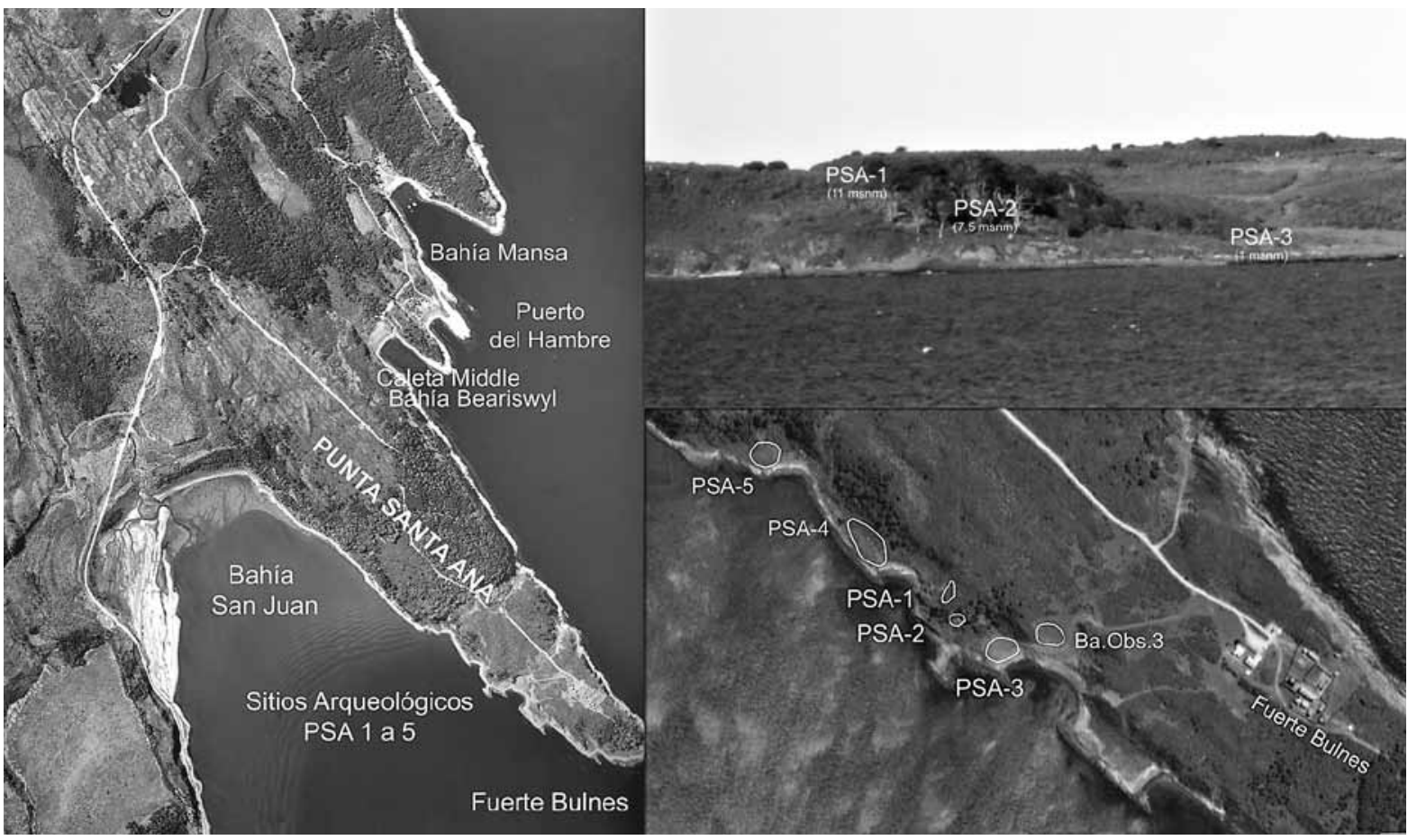

Fig. 2. Punta Santa Ana y la localización de los sitios arqueológicos: vista de detalle de fotografía aérea, fotografía desde bahía San Juan y fotografía satelital (Google Earth), respectivamente. 


\section{ANTECEDENTES}

La Punta Santa Ana corresponde a una proyección de tierra que se interna aproximadamente $2,5 \mathrm{~km}$ hacia el estrecho de Magallanes, en dirección sudeste, conformando el límite norte de la bahía San Juan. Es una formación geológica cuya base está asentada sobre rocas sedimentarias del Cretácico. La información paleoambiental de tiempos finipleistocénicos y de inicios del Holoceno destaca una importante actividad neotectónica en el área, generando hundimiento de terreno durante el Holoceno temprano. El ambiente actual es de bosque caducifolio, predominando el bosque de Nothofagus sp., que se habría instalado en la zona con posterioridad a ca. 8500 años AP. En una época cercana a esta última fecha se registra el inicio de la transgresión marina del Holoceno medio, datada entre 8265 y 3900 años AP, con un máximo transgresivo datado hacia los 6450 años AP (Bentley y McCulloch 2005; McCulloch y Davies 2001).

Los trabajos del arqueólogo Omar OrtizTroncoso, a comienzos de la década de 1970, le permitieron detectar y excavar el yacimiento Punta Santa Ana 1. Dichas investigaciones convirtieron esta localidad en un hito clave para el conocimiento de una de las fases culturales más tempranas de la prehistoria patagónica, conocida posteriormente como la Tradición Cultural Englefield. Se trata de cazadores-recolectores y pescadores especializados en recursos marinos (Ortiz-Troncoso 1975, Legoupil y Fontugne 1997, San Román 2010).

A partir de recientes trabajos de prospección (San Román et al. 2009), identificamos dos sitios arqueológicos que se estudiaron in extenso en el marco de éste proyecto. Los yacimientos Punta Santa Ana 2 (PSA-2) y Punta Santa Ana 3 (PSA3) se ubican en la costa sur de la punta, mirando hacia la bahía San Juan y la desembocadura del río homónimo. Son sitios de campamento caracterizados por basurales conchíferos. Igualmente, se registraron y sondearon los sitios PSA-4 y PSA-5, ubicados en pequeñas caletas inmediatamente al oeste de PSA-1 (Fig. 2).

El presente trabajo presenta los resultados de una comparación diacrónica entre las ocupaciones prehistóricas de la Punta Santa Ana, analizando algunos elementos del contexto general, y principalmente los restos culturales recolectados en las excavaciones extensivas de los yacimientos PSA-1 (Ortiz-Troncoso 1975), PSA-2 y PSA-3. Se resumen los principales resultados de los análisis zooarqueológicos y tecnológicos efectuados en estos conjuntos, comparando y discutiendo las principales tendencias temporales registradas, las que permiten sostener importantes inflexiones y particularidades de cada componente arqueológico registrado.

\section{RESULTADOS}

\section{Depósitos y Cronología}

El sitio PSA-1 se emplaza sobre una explanada por sobre los $11 \mathrm{msnm}$. El contexto general describe un depósito de conchal conformado por basura doméstica y diferentes lentes de concha, carbones, cenizas y gravas, entre otras, que contenían abundantes restos de fauna, materiales líticos e instrumentos óseos. El sitio fue excavado siguiendo la estratigrafía natural del depósito, registrando un espesor máximo para el conchal de $55 \mathrm{~cm}$. La excavación abarcó una superficie de $29 \mathrm{~m}^{2}$. Entre los hallazgos, destacan los restos de un esqueleto humano de sexo femenino, depositado sin ajuar entre los sedimentos de los niveles de conchal (OrtizTroncoso 1975, 1979).

Un reciente estudio de la micromorfología de los sedimentos del sitio PSA-1 (Arroyo-Kalin y French 2012) muestra que el principal contraste entre los diferentes estratos de conchas dice relación con el estado de alteración térmica de las mismas y el contenido de carbón de tamaño microscópico en estos sedimentos. El estudio no detecta señales de pisoteo en los sedimentos analizados y evidencia una casi completa ausencia de agregados de suelo y/o sedimentos intrusivos en los estratos del depósito. Estas observaciones son coherentes con ocupaciones extraordinariamente acotadas en el tiempo y un enterramiento relativamente rápido de los depósitos. El estudio micromorfológico también identifica evidencia de prácticas culturales: el registro de pequeñas lentes de gravilla asociadas a una estructura de combustión in situ permite interpretar diversos estratos que contienen dichas gravillas, conchas térmicamente alteradas y abundantes fragmentos de carbón como restos de la limpieza de estructuras de combustión. La estratigrafía de estos lentes sugiere su acumulación como resultado 
de las actividades de manutención del espacio en el sitio. El estudio también identifica las superficies enterradas por los depósitos de conchales como perfiles truncados desde los que se ha removido el horizonte húmico $\mathrm{y}$, probablemente, una parte del horizonte A original del lugar previo a la acumulación de vestigios arqueológicos. Esta observación constituye un importante antecedente que pone de relieve las características de prácticas culturales de preparación o remoción de suelo y capa vegetal para la instalación del campamento.

La excavación del sitio PSA-2 se realizó entre los años 2008 y 2009, abarcando un área total de $25 \mathrm{~m}^{2}$. Este yacimiento se ubica sobre una terraza marina a una altura de $7,5 \mathrm{msnm}$. El sitio se caracteriza por depósitos de conchal, con la formación de al menos dos pequeños montículos. Durante el proceso de excavación se pudo caracterizar un depósito homogéneo de conchal, de espesor variable y sin evidencias de hiatos estratigráficos. Las dataciones de conchas efectuadas en la base y techo del depósito permitieron constatar un breve lapso temporal implicado en la formación del sitio (Tabla 1).

Para PSA-3, la muestra excavada sumó un total de $17,5 \mathrm{~m}^{2}$. El sitio se encuentra a $1 \mathrm{msnm}$ y su borde este ha sido activamente erosionado por las mareas. A partir de la evidencia estratigráfica se constató la alteración de las capas superficiales, producto de remociones de sedimentos y tráfico de vehículos asociada a labores de reconstrucción del Fuerte Bulnes, efectuada a mediados del siglo pasado. La excavación permitió identificar al menos 3 lentes monticulares de conchales intercalados y uno más discreto inserto bajo la capa de gravas y guijarros de una paleoplaya que subyace a los depósitos arqueológicos. También se recopilaron antecedentes fotográficos (Tobar et al. 2008) y evidencias estratigráficas (basurales subactuales) de eventos de disturbación del yacimiento. Es por esto que se desarrollaron una serie de actividades de caracterización estratigráfica -como la limpieza de perfil expuesto- y espacial del sitio, con miras a seleccionar el lugar de excavación. Los criterios de interés fueron la integridad de los depósitos, la distribución y densidad de material cultural en estratigrafía.

Las potencias máximas de los sitios varían entre 50 a $55 \mathrm{~cm}$ en PSA-1 y PSA-2, respectivamente, y $90 \mathrm{~cm}$ alcanzados en PSA-3. Esta información y los resultados del estudio arqueozoológico de los materiales de PSA-1 han permitido plantear que el sitio de canoeros tempranos correspondería a locaciones de campamento de uso esporádico o de tránsito entre nodos más importantes (San Román 2010). Una inferencia similar se puede plantear como hipótesis en el caso de PSA-2.

La cronología inicial asignada a PSA-1 tenía un rango amplio, llegando a cifras cercanas a 900 años de diferencia (cf. Ortiz-Troncoso 1975, SotoHeim 1992). No obstante, información reciente

Tabla 1. Dataciones absolutas realizadas en los sitios PSA-1, PSA-2 y PSA-3.

\begin{tabular}{|c|c|c|c|c|c|c|c|}
\hline \multirow{2}{*}{$\begin{array}{l}\text { Sitio } \\
\text { PSA-1 }\end{array}$} & \multirow{2}{*}{\begin{tabular}{|l|} 
Material \\
conchas \\
\end{tabular}} & \multicolumn{3}{|c|}{$\begin{array}{c}\text { Edad Convencional } \\
\text { años AP }\end{array}$} & \multirow{2}{*}{$\begin{array}{c}\text { d13C (\%o) } \\
\text { s/n ref }\end{array}$} & \multirow{2}{*}{\begin{tabular}{|l|} 
Código \\
Gif-2928
\end{tabular}} & \multirow{2}{*}{$\begin{array}{r}\text { Referencia } \\
\text { Ortiz-Troncoso } 1975\end{array}$} \\
\hline & & 5620 & \pm & 120 & & & \\
\hline & conchas & 6410 & \pm & 70 & $\mathrm{~s} / \mathrm{n}$ ref & GrN-7612 & Ortiz-Troncoso 1977-78 \\
\hline & esqueleto humano * & 6540 & \pm & 110 & $\mathrm{~s} / \mathrm{n}$ ref & Gif s/n ref & Soto-Heim 1992 \\
\hline & esqueleto humano * & 6290 & \pm & 50 & $-11,6$ & Beta-252913 & San Román 2010 \\
\hline & hueso guanaco & 6330 & \pm & 50 & -21 & Beta-252914 & San Román 2010 \\
\hline \multirow[t]{4}{*}{ PSA-2 } & carbón & 2690 & \pm & 50 & $-25,3$ & Gif-12223 & San Román et al. 2009 \\
\hline & conchas & 3200 & \pm & 40 & 1,78 & Gif-12255 & San Román et al. 2009 \\
\hline & conchas & 3280 & \pm & 40 & 0,7 & Beta-271325 & Este trabajo/Techo depósito \\
\hline & conchas & 3340 & \pm & 40 & $-0,2$ & Beta-271326 & Este trabajo/Base depósito \\
\hline \multirow[t]{3}{*}{ PSA-3 } & carbón & 715 & \pm & 40 & $-25,43$ & Gif-12224 & San Román et al. 2009 \\
\hline & conchas & 1305 & \pm & 30 & 1,46 & Gif-12256 & San Román et al. 2009 \\
\hline & húmero humano & 1010 & \pm & 30 & $-11,8$ & Beta-316350 & Este trabajo \\
\hline \multirow[t]{2}{*}{ PSA-4 } & conchas & 2900 & \pm & 60 & 0,7 & Beta-262403 & Este trabajo \\
\hline & conchas & 2870 & \pm & 50 & 1,4 & Beta-259455 & Este trabajo \\
\hline PSA-5 & conchas & 3260 & \pm & 50 & 1 & Beta-271327 & Este trabajo \\
\hline
\end{tabular}

Corresponde al mismo individuo. 
aclara las incongruencias evidenciadas y vuelve dudosa la fecha más joven de 5620 años, ya que la mayoría de las dataciones se concentran alrededor de los 6300 años antes del presente (Tabla 1). Lo anterior concuerda con la información contextual y estratigráfica, que señala un período de formación breve, producto de una ocupación acotada en el tiempo. Una situación similar se observa en PSA-2, con un lapso de formación muy breve, entre techo y base del conchal, de aproximadamente 140 años radiocarbónicos. El contexto igualmente avala esta inferencia. El tiempo de formación para PSA-3 aún no se ha determinado, pero es defendible la idea de que el tiempo implicado sería corto pero mayor al observado en los sitios más antiguos. A partir de las dataciones sobre carbones y un resto humano detectamos cerca de 300 años de diferencia, aunque la información isotópica para el hueso humano supone una dieta marcadamente marina, hecho que sugiere un envejecimiento de la edad por efecto reservorio (Tabla 1 ).

Con un fin comparativo, el análisis de los materiales líticos y restos óseos consideró las muestras recolectadas en cada sitio como un conjunto sin subdivisiones espaciales ni estratigráficas. Es decir, la muestra de materiales de cada sitio fue comparada como una unidad. En términos de integridad cronológica, creemos defendible el criterio utilizado, ya que cada conjunto promediaría lapsos de tiempo bastante cortos.

\section{Estrategias de subsistencia}

Para los tres yacimientos se observa la dominancia de recursos marinos y/o litorales, aunque se describen importantes cambios relativos a predominancia, diversidad e intensidad en la explotación de éstos (Tabla 2, Figs. 3 y 4).

En relación a los recursos ictiológicos (Tabla 3), una primera tendencia tiene relación a la disminución en la importancia de los peces en la dieta para momentos tardíos, a partir de la ostensible disminución del porcentaje de restos en los depósitos analizados y las proporciones de aves y mamíferos. En cuanto a la diversidad de taxones capturados, PSA-1 presenta el espectro más rico, evidenciando la explotación de diferentes ambientes. En PSA-1 predomina la especie demersal Salilota australis (brótula), representada por la mitad de los restos estudiados. La otra mitad está constituida por especies que habitan ambientes de orilla rocosos o pedregosos (Zoarcidos y Patagonotothen sp.), como también de ambientes de desembocaduras (Eleginops maclovinus, róbalo). Igualmente, destacan restos de elasmobranquios que no aparecen en las ocupaciones posteriores y escasamente han sido hallados en otros sitios de la región, entre estos algún taxón del súper orden Batoidea, probablemente algún Rajiforme de ambientes de fondo fangoso o arenoso. Además hay restos de Squaliforme (tiburón) pequeño. No obstante, esta variabilidad de los ambientes explotados no es general a los sitios de canoeros tempranos, ya que en el sitio Pizzulic 2, ubicado en el mar de Otway, observamos énfasis absoluto en la pesca de Salilota australis (Torres y Ruz 2011).

Para PSA-2 se observa un marcado énfasis en la pesca de Salilota australis, con una bajísima representación de otros taxa, entre los que se incluyen Patagonotothen sp. y Macrorunus magellanicus (merluza de cola). Este último pudo ser capturado marginalmente junto a Salilota australis. Este énfasis, al parecer, es muy característico en otros sitios insulares de similares cronologías (Legoupil et al.2011). Este yacimiento presenta las densidades más altas de los tres conjuntos (Tabla 2).

Para momentos tardíos, el sitio PSA-3 da muestras de un cambio significativo. Salilota australis fue escasamente explotada, en cambio, especies como Eleginops maclovinus (róbalo) y Odontesthes sp. (pejerrey) muestran un predominio total. Si bien, los análisis ictioarqueológicos aún no se han completado, la evidencia muestra importantes inflexiones a lo largo de la secuencia temporal.

En cuanto a la explotación de aves, una primera constatación está dada por la baja densidad de sus restos durante momentos tempranos (PSA-1), en comparación a las frecuencias registradas en los otros yacimientos (PSA-2 y PSA-3) [Tabla 2 y 4]. En relación a taxones dominantes, Phalacrocorax sp. (cormorán) ocupa el primer lugar en PSA-1 y PSA3 , en cambio PSA-2 está dominado por restos de procellariiformes (Puffinus sp., fardelas). En términos generales, se observa una mayor densidad de $\mathrm{NISP} / \mathrm{m}^{3}$ y diversidad de taxones explotados en la ocupación tardía (PSA-3), destacando que PSA-2 se distingue notoriamente de los demás conjuntos por una muy baja frecuencia de Anseriformes. 


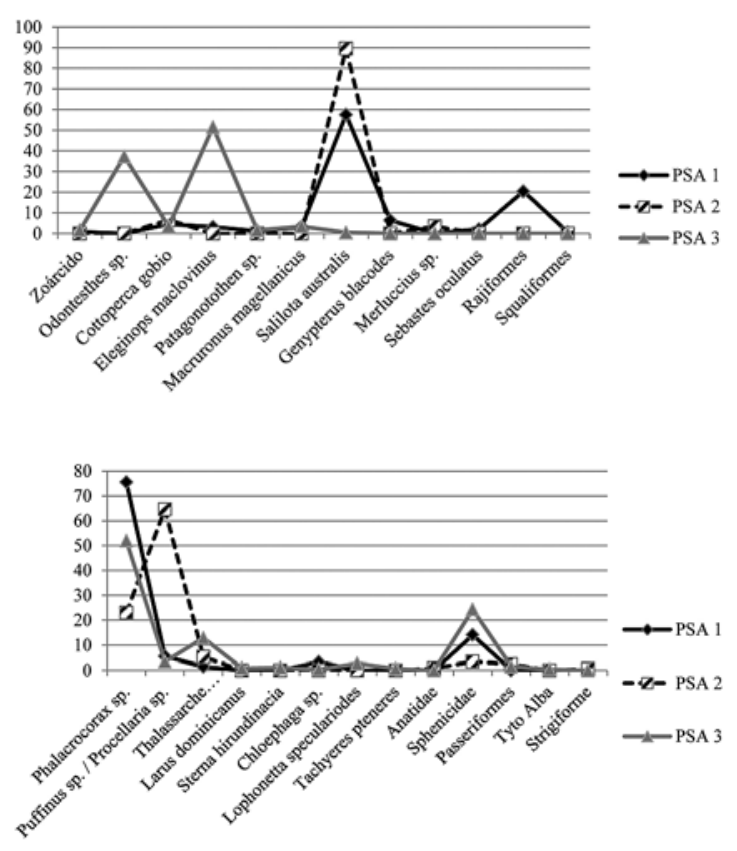

Tabla 2. Resumen por categoría, muestra de estudio, NISP y densidad de restos de fauna analizada por sitio.

\begin{tabular}{|c|c|c|c|}
\hline & \multicolumn{3}{|c|}{ MUESTRA DE ESTUDIO } \\
\hline & PSA-1 & PSA-2 & PSA-3 \\
\hline Peces & $\begin{array}{l}27 \mathrm{~m}^{2} \text { (recol. select. } \\
\text { Columna A) y } 1 \mathrm{~m}^{2 *}\end{array}$ & $1 \mathrm{~m}^{2^{*}}$ & $1 \mathrm{~m}^{2 *}$ \\
\hline Aves & $29 \mathrm{~m}^{2}$ & $4 \mathrm{~m}^{2}$ & $5,25 \mathrm{~m}^{2}$ \\
\hline \multirow[t]{3}{*}{ Mamíferos } & $29 \mathrm{~m}^{2}$ & $25 \mathrm{~m}^{2}$ & $17,5 \mathrm{~m}^{2}$ \\
\hline & \multicolumn{3}{|c|}{ NISP Total } \\
\hline & PSA-1 & PSA-2 & PSA-3 \\
\hline Peces & 2375 & 964 & 437 \\
\hline Aves & 811 & 2155 & 1618 \\
\hline \multirow[t]{3}{*}{ Mamíferos } & 806 & 160 & 2171 \\
\hline & \multicolumn{3}{|c|}{ DENSIDAD NISP $/ \mathrm{m}^{3 * * * *}$} \\
\hline & PSA-1 & PSA-2 & PSA-3 \\
\hline Peces & 42,4 & 1752,7 & 485,6 \\
\hline Aves & 14,0 & 296,3 & 277,4 \\
\hline Mamíferos & 13,9 & 3,5 & 111,7 \\
\hline
\end{tabular}

Recolección sistemática malla $3 \mathrm{~mm}$, y muestra basada en Ortiz-Troncoso 1979, Torres y Ruz 2011.

* Las muestras corresponden a la totalidad del material de PSA-1 excavado por Ortiz-Troncoso (1975), basado en Lefevre (1989). Las muestras de PSA-2 y PSA-3 corresponden al área de excavación de trincheras.

*** Análisis basado en el total de la muestra recuperada en excavaciones y sondeos, y resultados de PSA-1 en San Román 2010.

*** Se consideró el espesor máximo de cada depósito.
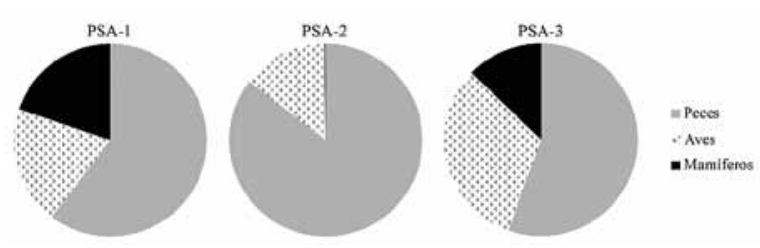

Fig. 3 Gráficos con frecuencia de \%NISP por sitio arqueológico, y según especies de peces, aves y mamíferos.

Los mamíferos marinos más abundantes en los tres yacimientos corresponden a pinnípedos, constatando que para PSA-1 y PSA-3 se han identificado restos de Arctocephalus australis (lobo fino) y Otaria flavescens (lobo común), mientras que en PSA-2 sólo se reconocieron elementos de esta última especie (Tabla 4). La densidad según NISP/ $\mathrm{m}^{3}$ es notablemente baja en PSA-2. En relación a otros mamíferos marinos, se registran escasos restos de delfines en PSA-1 y PSA-3. Algo similar ocurre con los restos de cetáceos, aunque éstos se asocian a la industria ósea. Con respecto a otros taxones, se observa una muy baja frecuencia de restos. En el caso de Lama guanicoe (guanaco), se registran restos en PSA-1 y PSA-3. Hippocamelus bisulcus

Fig. 4 Representación gráfica de densidad de NISP de peces, aves y mamíferos según $\mathrm{m}^{3}$.

-huemul- aparece restringido al componente tardío (PSA-3) y los cánidos se registran en PSA-1 y PSA-2, identificando Duscicyon culpaeus para este último yacimiento (zorro colorado). Entre los elementos de interés es destacable la ínfima frecuencia de artiodáctilos en PSA-2. El único resto corresponde a un fragmento de instrumento sobre diáfisis y no se relacionaría con obtención local de este animal. En relación a taxones incidentales, se registró un resto asignado a Lontra sp. (PSA-3) y otro de Myocastor coipus (PSA-1).

La explotación de moluscos, en los tres sitios, constata el uso del intermareal rocoso, predominante en la Punta Santa Ana. El taxón más conspicuo en todos los depósitos es Mytilus edulis 
chilensis (chorito o mejillón), observándose algunas variaciones en el ranking de frecuencias de taxones secundarios (San Román et al. 2009), entre los cuales se identifican Fisurella sp. (lapa), Nacella sp. (maucho), Poliplacophora sp. (chitón), Trophon sp., Acanthina sp. (caracoles), Loxechinus albus (erizo), cirripedios y otros fragmentos indeterminados. Interesante es destacar la presencia de varios fragmentos y restos enteros que corresponden a un mínimo de 4 individuos de Coronula sp. en PSA-3. Este cirripedio ha sido previamente identificado en el canal Beagle, en el sitio Mischiuen I Componente Reciente, con fechados de 1.060 y 890 años AP. Las especies locales de Coronula sp. son todas epibiontes de cetáceos, que se fijan en cabeza y aletas. La mayoría de los casos registrados actualmente se fijan en ballenas de gran tamaño, preferentemente jorobadas (Megaptera novaeangliae). Considerando esta información, se ha utilizado este criterio como indicador de presencia de cetáceo (ballena jorobada) y del transporte y consumo de su carne (Piana et al. 2004, En Piana et al. 2007).

\section{Tecnología Ósea}

El sitio PSA-1 presenta un conjunto de 39 artefactos e instrumentos característicos de ocupaciones tempranas (Ortiz-Troncoso 1975). Destacan una serie de piezas, tales como los cinceles, confeccionados sobre ulna de pinnípedo y en un caso, sobre diáfisis de tibia de Lama guanicoe, y además, cuñas sobre hueso de cetáceo. Entre los cabezales de arma se registró un extremo distal de arpón monodentado, con decoración incisa, y un arpón monodentado de base cruciforme. Otro tipo de arpón corresponde a los multidentados con base aguzada. También se incluye otra gama de instrumentos como los retocadores sobre metapodio de guanaco, punzones sobre tibiotarso y piezas aguzadas sobre radio de Phalacrocorax sp. (Fig. 5).

Otros elementos incluyen seis fragmentos de diáfisis de hueso largo de ave finamente grabados y que podrían corresponder a un mismo artefacto (Fig. 5g). Finalmente, se describen algunos huesos con diferentes modificaciones, tales como un hueso de pinnípedo de sección lenticular que presenta pulimento, un fragmento de punta -probablemente un ápice de arpón o de punzón- y una pieza de sección elíptica de forma general cuadrangular, que pudo corresponder a los primeros estadios de manufactura de un arpón.

PSA-2 incluye una limitada diversidad tipológica de instrumentos sobre hueso, en donde destacan las piezas de extremo aguzado sobre huesos largos de ave (Fig. 6). El conjunto más conspicuo está formado por diáfisis con un extremo fracturado transversalmente y el otro con una punta muy aguzada $(n=52)$. Este tipo de piezas está hecho predominantemente sobre

Tabla 3. Frecuencia de restos ictioarqueológicos recuperados desde los yacimientos de Punta Santa Ana.

\begin{tabular}{|c|c|c|c|c|c|c|c|c|}
\hline \multirow[b]{3}{*}{ TAXÓN } & \multicolumn{4}{|c|}{ PSA-1 } & \multirow{2}{*}{\multicolumn{2}{|c|}{$\begin{array}{c}\text { PSA-2 } \\
1 \mathrm{~m}^{2}\end{array}$}} & \multirow{2}{*}{\multicolumn{2}{|c|}{$\begin{array}{c}\text { PSA-3 } \\
1 \mathrm{~m}^{2}\end{array}$}} \\
\hline & \multicolumn{2}{|c|}{$\mathbf{A}^{1}$} & \multicolumn{2}{|c|}{$1 \mathbf{m}^{2}$} & & & & \\
\hline & NISP & NISP\% & NISP & NISP\% & NISP & NISP\% & NISP & NISP\% \\
\hline Indeterminado talla pequeña & - & - & - & - & 4 & 0,41 & 3 & 0,68 \\
\hline Zoárcido & 18 & 1,45 & - & - & - & - & 7 & 1,6 \\
\hline Odontesthes sp. & - & - & - & - & - & - & 163 & 37,29 \\
\hline Cottoperca gobio & 32 & 2,59 & 76 & 6,66 & 63 & 6,53 & 15 & 3,43 \\
\hline Eleginops maclovinus & 60 & 4,86 & 18 & 1,57 & - & - & 225 & 51,48 \\
\hline Patagonotothen sp. & - & - & 25 & 2,19 & - & - & 7 & 1,6 \\
\hline Macruronus magellanicus & 65 & 5,26 & 5 & 0,43 & - & - & 15 & 3,43 \\
\hline Salilota australis & 689 & 55,83 & 720 & 63,1 & 864 & 89,62 & 2 & 0,45 \\
\hline Genypterus blacodes & 114 & 9,23 & 33 & 2,89 & - & - & - & - \\
\hline Merluccius sp. & 2 & 0,16 & 1 & 0,08 & 33 & 3,42 & - & - \\
\hline Sebastes oculatus & 36 & 2,91 & 12 & 1,05 & - & - & - & - \\
\hline Rajiformes & 218 & 17,66 & 236 & 20,68 & - & - & - & - \\
\hline Squaliformes & - & - & 15 & 1,31 & - & - & - & - \\
\hline TOTAL & 1234 & 100 & 1141 & 100 & 964 & 100 & 437 & 100 \\
\hline
\end{tabular}

1 La columna "A" corresponde a materiales recolectados selectivamente durante la excavación de PSA-1 (Ortiz Troncoso 1979, Torres y Ruz 2011). 


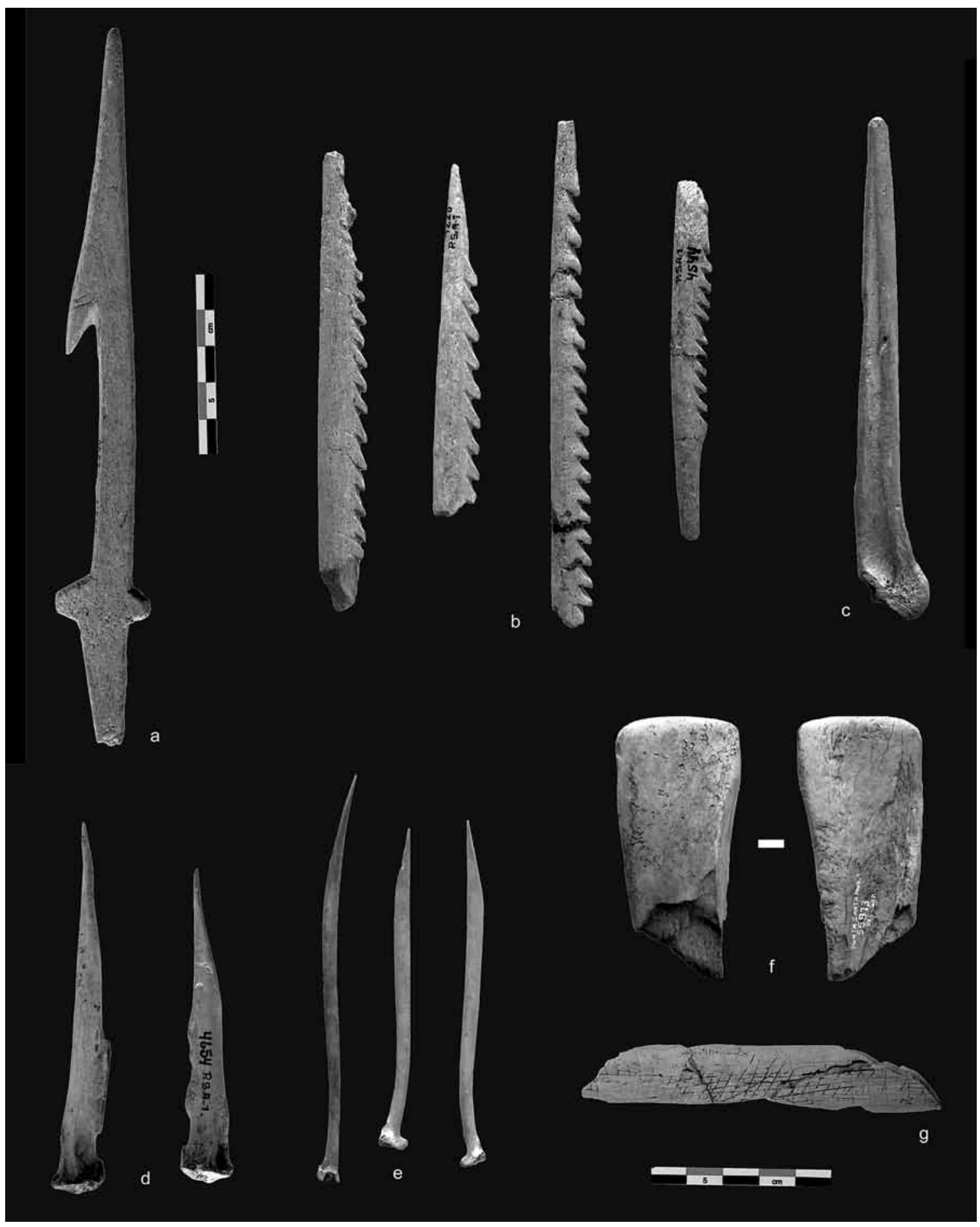

Fig. 5. Instrumentos de hueso del sitio PSA-1: a) arpón monodentado de base cruciforme con decoración incisa, b) cuatro arpones multidentados de base aguzada fracturados, c) retocador sobre metatarso de guanaco, d) dos punzones sobre tibiotarso de ave, e) tres piezas aguzadas sobre radio de Phalacrocorax sp., f) cincel sobre tibia de guanaco y g) fragmento de diáfisis de hueso largo de ave con decoración. 
Tabla 4. Restos faunísticos recuperados desde los sitios PSA-1, PSA-2 y PSA-3.

\begin{tabular}{|c|c|c|c|c|c|c|}
\hline \multirow[b]{2}{*}{ TAXON } & \multicolumn{2}{|c|}{ PSA-1 } & \multicolumn{2}{|c|}{ PSA-2 } & \multicolumn{2}{|c|}{ PSA-3 } \\
\hline & NISP & \%NISP & NISP & \%NISP & NISP & \%NISP \\
\hline Arctocephalus australis & 8 & 0,99 & - & - & 39 & 1,80 \\
\hline Otaria flavescens & 1 & 0,12 & 50 & 31,25 & 43 & 1,98 \\
\hline Otariidae & 691 & 85,74 & 95 & 59,37 & 1944 & 89,54 \\
\hline Delfinidae & 1 & 0,12 & - & - & 18 & 0,83 \\
\hline Cetacea & 22 & 2,73 & - & - & 17 & 0,78 \\
\hline Lontra sp. & - & - & - & - & 1 & 0,05 \\
\hline Lama guanicoe & 46 & 5,71 & - & - & 1 & 0,05 \\
\hline Hippocamelus bisulcus & - & - & - & - & 33 & 1,52 \\
\hline Artiodactyla & 30 & 3,72 & 1 & 0,62 & 75 & 3,45 \\
\hline Canidae & 6 & 0,74 & 14 & 8,75 & - & - \\
\hline Myocastor coipus & 1 & 0,12 & - & - & - & - \\
\hline SUBTOTAL & 806 & 100 & 160 & 100 & 2171 & 100 \\
\hline Mamíferos indeterminados & 260 & - & 7 & - & 361 & - \\
\hline TOTAL MAMÍFEROS & 1066 & - & 167 & - & 2532 & - \\
\hline Phalacrocorax sp. & 462 & 75,49 & 87 & 22,96 & 246 & 51,90 \\
\hline Puffinus sp. / Procellaria sp. & 34 & 5,56 & 245 & 64,64 & 16 & 3,38 \\
\hline Thalassarche sp./Macronectes g. & 9 & 1,47 & 20 & 5,28 & 61 & 12,87 \\
\hline Larus dominicanus & - & - & - & - & 4 & 0,84 \\
\hline Sterna hirundinacia & - & - & - & - & 5 & 1,05 \\
\hline Chloephaga sp. & 20 & 3,27 & - & - & 2 & 0,42 \\
\hline Lophonetta speculariodes & - & - & - & - & 13 & 2,74 \\
\hline Tachyeres pteneres & 1 & 0,16 & - & - & 3 & 0,63 \\
\hline Anatidae & - & - & 3 & 0,79 & - & - \\
\hline Sphenicidae & 86 & 14,05 & 13 & 3,43 & 115 & 24,26 \\
\hline Passeriformes & - & - & 9 & 2,37 & 7 & 1,48 \\
\hline Tyto alba & - & - & - & - & 2 & 0,42 \\
\hline Strigiforme & - & - & 2 & 0,53 & - & - \\
\hline SUBTOTAL & 612 & 100 & 377 & 100 & 474 & 100 \\
\hline Aves indeterminadas & 199 & - & 1778 & - & 1144 & - \\
\hline TOTAL AVES $^{2}$ & 811 & - & 2155 & - & 1618 & - \\
\hline TOTAL GENERAL (NR) & \multicolumn{2}{|c|}{1877} & \multicolumn{2}{|c|}{2322} & \multicolumn{2}{|c|}{4150} \\
\hline
\end{tabular}

tibiotarsos y radios. Se observa que este grupo de instrumentos se agrupa en al menos tres rangos de tamaño: puntas largas $(10-6 \mathrm{~cm})$, medianas $(6-4 \mathrm{~cm}$.) y cortas $(4-2 \mathrm{~cm})$. Además, se describen punzones sobre húmeros, los que conservan su epífisis proximal $(n=4)$ o distal $(n=1)$, identificándose Puffinus $s p$. como soporte. Se agregan algunos elementos aguzados sobre radio de Phalacrocorax sp. que preservan una de sus epífisis (distal o proximal). Algunos fragmentos de diáfisis que preservan un extremo aguzado pueden corresponder a piezas rotas, y un fragmento longitudinal de diáfisis de ave de gran tamaño que presenta ambos extremos aguzados. Finalmente, se registró un fragmento de diáfisis de hueso largo de artiodáctilo que preservó una limitada porción formatizada en uno de sus extremos, de sección circular.

El yacimiento tardío PSA-3 presenta arpones monodentados de espaldón simple, describiéndose dos tipos: uno corto y macizo con el borde interno del espaldón paralelo al borde interno del diente $(\mathrm{n}=2)$, el otro tipo es de mayor longitud, con el borde interior del espaldón recto ( $n=1$ ) (Fig. 7). Ambos están confeccionados sobre hueso de cetáceo. Además, se describen cuñas y fragmentos de éstas, y un fragmento de diáfisis con ambos extremos cortados

2 La información de avifauna de PSA-1 está basada en datos de Lefevre (1989) e incluye la totalidad de restos recuperados de la excavación (29 m2). Los datos de avifauna presentados para PSA-2 y PSA-3 se basan en una muestra de 4 y 5,25 m², respectivamente. 


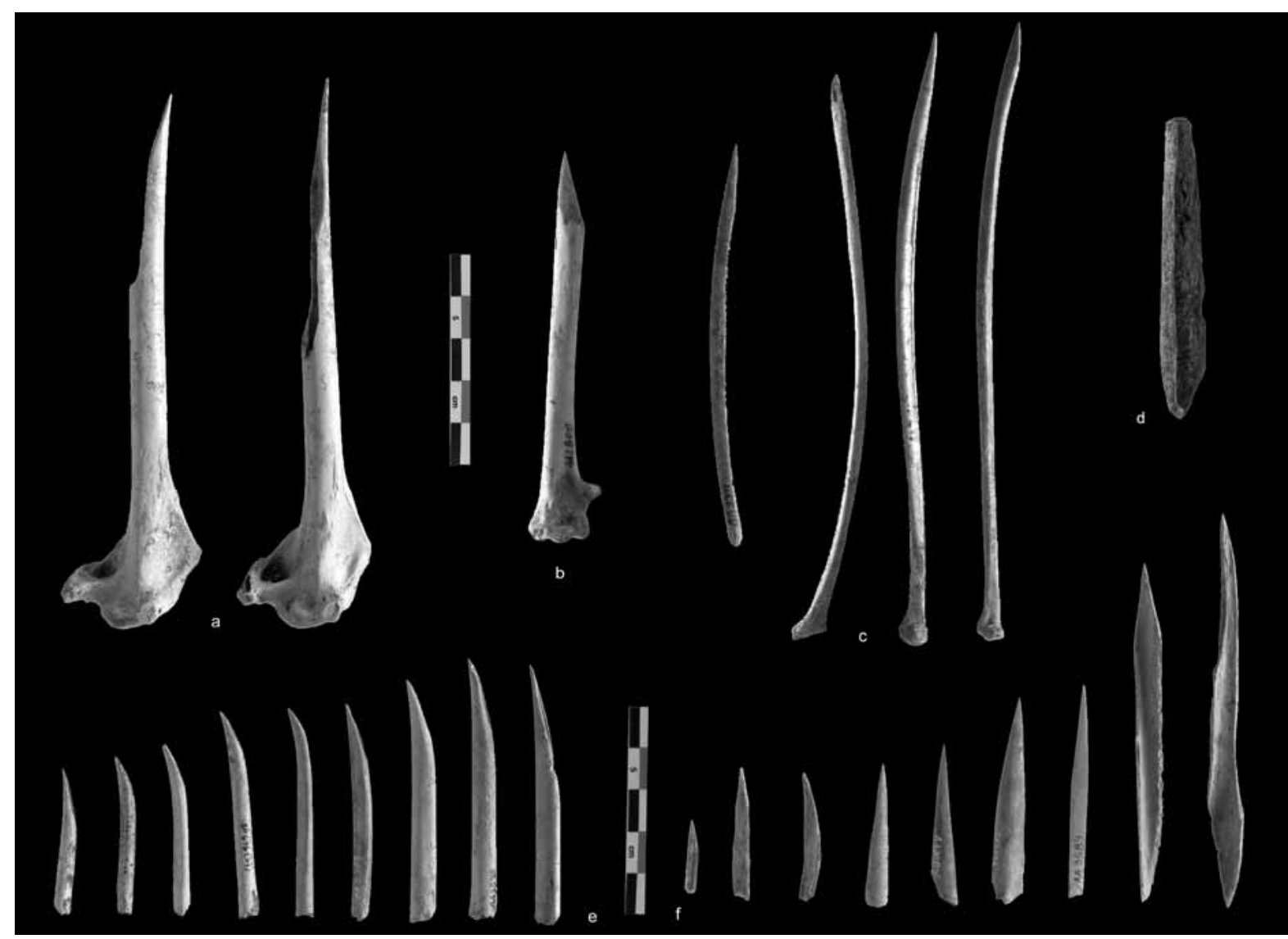

Fig. 6. Instrumentos óseos de PSA-2: a) y b) tres punzones sobre húmero de Puffinus sp. (fardela), c) cuatro aguzados sobre radio de Phalacrocorax sp., d) fragmento de instrumento sobre diáfisis de Artiodactyla, e) y f) puntas aguzadas sobre hueso largo de ave.

perimetralmente y con sus bordes pulidos, confeccionados sobre huesos de cetáceo. En relación a las piezas aguzadas, punzones o leznas, se describen huesos largos de aves, principalmente húmeros $(\mathrm{n}=4)$ y tibiotarsos $(n=4)$ de Phalacrocorax sp., Tachyeres sp. y Procelariiformes. Estas piezas preservan la epífisis proximal y las puntas se emplazan en los extremos distales de las diáfisis, a las que se agregan fragmentos de puntas que corresponderían a piezas fracturadas. Se describe un retocador y una pieza aguzada en uno de sus extremos, de sección circular, confeccionada sobre un baguette. Ambos estarían fabricados sobre huesos largos de Artiodactyla. La obtención del soporte para confeccionar esta última pieza se asocia a una técnica de extracción que incluye el marcado longitudinal sobre metapodios, que permitiría la extracción de baguette alargados y rectos. Finalmente, se describe una epífisis proximal de tibia de Lama guanicoe con marcado y corte perimetral (Fig. 7g).

\section{Tecnología Lítica}

Según Ortiz-Troncoso (1975) y las tablas de datos de Schidlowsky (1999), la industria lítica de PSA-1 está representada por 162 piezas, de las cuales 52 están confeccionadas en obsidiana verde, es decir el 32,1\%. Las categorías de piedra tallada incluyen 28 instrumentos formatizados, 95 lascas y otros desechos. Los restantes 39 artefactos son pesas de red, percutores y otras piezas de piedra pulida, piqueteada o guijarros utilizados $(24,1 \%)$. La relación entre los instrumentos formatizados por talla y las lascas es cercana a 1:3; siendo altísima la proporción de instrumentos en relación a los desechos de talla (Tabla 5). 


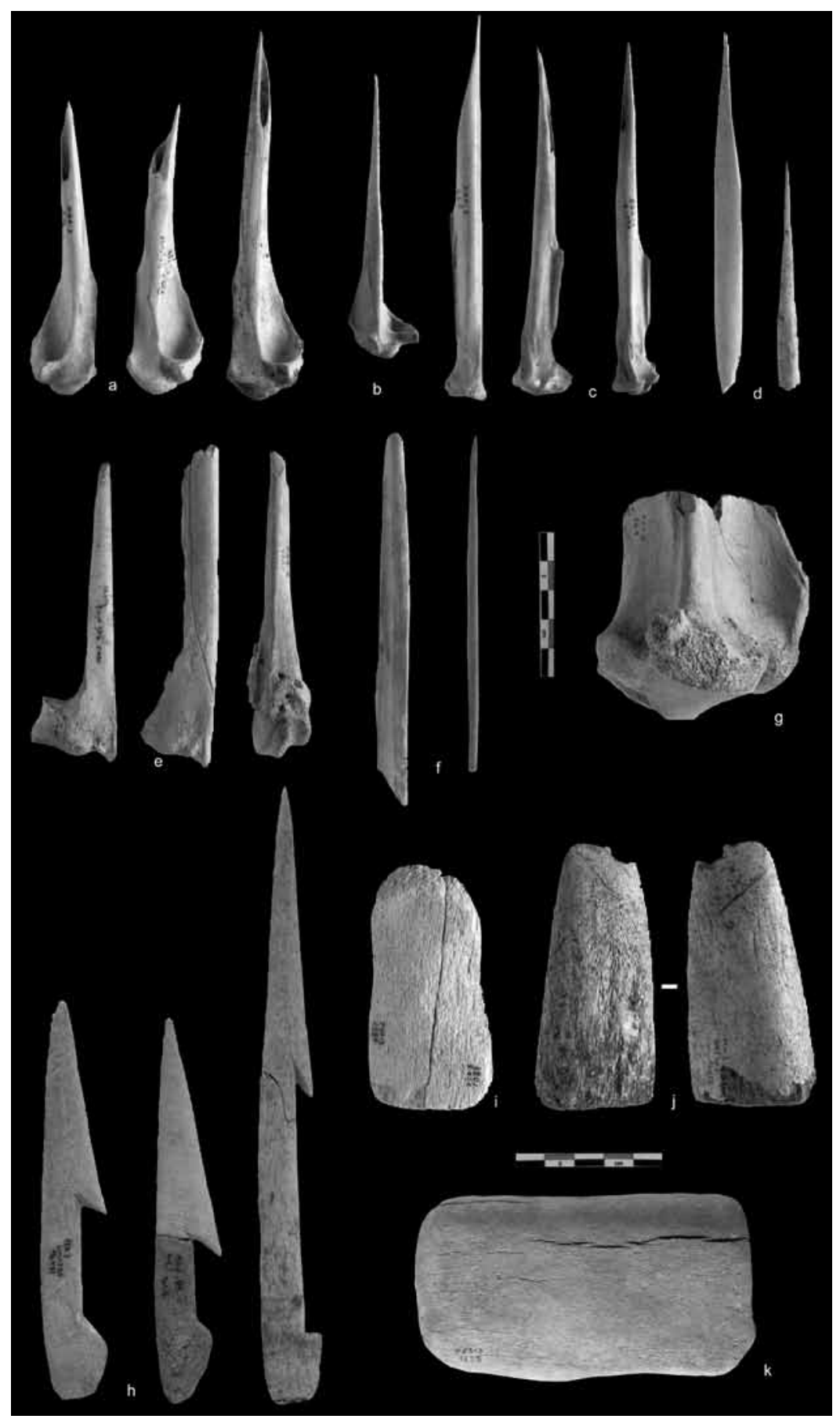

Fig. 7. Instrumentos de hueso del sitio PSA-3: a) y b) cuatro punzones sobre húmero de ave, c) tres punzones sobre tibiotarso de ave, d) dos fragmentos aguzados, e) metapodios con trazas de marcado longitudinal y con extracción controlada de diáfisis, f) retocador e instrumento aguzado sobre diáfisis de hueso largo de Artiodactyla, g) machacador o epífisis proximal de tibia de guanaco con corte perimetral, h) dos arpones monodentados de espaldón simple, corto y macizo, y un arpón monodentado de espaldón simple alargado y con borde interno de espaldón recto, i) instrumento sobre hueso de cetáceo con seccionamiento distal y marcas de trituramiento en una cara, j) fragmento de cuña sobre hueso de cetáceo, y k) instrumento indeterminado sobre hueso de cetáceo. 
Tabla 5. Materiales líticos de PSA-1 por categoría y materia prima, según Ortiz-Troncoso 1975 y Schidlowsky 1999.

\begin{tabular}{|c|c|c|c|c|}
\hline \multirow[t]{2}{*}{ CATEGORÍA } & \multicolumn{2}{|c|}{ MATERIA PRIMA } & \multirow[t]{2}{*}{ TOTAL } & \multirow[t]{2}{*}{$\%$} \\
\hline & $\begin{array}{l}\text { Obsidiana } \\
\text { verde }\end{array}$ & Otras & & \\
\hline \multicolumn{5}{|l|}{ Instrumentos formatizados por talla } \\
\hline Cuchillo sobre lasca retocada & 4 & 6 & 10 & 6,17 \\
\hline Cuchillo sobre lámina retocada & 1 & 0 & 1 & 0,62 \\
\hline Punta sobre lasca & 1 & 0 & 1 & 0,62 \\
\hline Punta bifacial sobre lasca & 2 & 0 & 2 & 1,23 \\
\hline Perforador sobre lasca & 1 & 0 & 1 & 0,62 \\
\hline Raedera & 0 & 5 & 5 & 3,09 \\
\hline Raspador & 0 & 1 & 1 & 0,62 \\
\hline Bifaz & 2 & 3 & 5 & 3,09 \\
\hline Bifaz-cuchillo sobre baguette & 1 & 0 & 1 & 0,62 \\
\hline Masa central retocada & 0 & 1 & 1 & 0,62 \\
\hline SUBTOTAL Instrumentos formatizados & 12 & 16 & 28 & 17,28 \\
\hline \multicolumn{5}{|l|}{ Instrumentos de piedra pulida, piqueteada o guijarros utilizados } \\
\hline Percutor & 0 & 3 & 3 & 1,85 \\
\hline Pesa de red & 0 & 6 & 6 & 3,70 \\
\hline Bola esferoidal con surco & 0 & 1 & 1 & 0,62 \\
\hline Alisador & 0 & 1 & 1 & 0,62 \\
\hline Otros indeterminados & 0 & 19 & 19 & 11,73 \\
\hline SUBTOTAL & 0 & 39 & 39 & 24,07 \\
\hline \multicolumn{5}{|l|}{ Otros artefactos tallados } \\
\hline Lasca & 38 & 51 & 89 & 54,94 \\
\hline Masa central astillada (núcleo?) & 1 & 2 & 3 & 1,85 \\
\hline Masa bruta (nódulo) & 1 & 2 & 3 & 1,85 \\
\hline SUBTOTAL Otros artefactos tallados & 40 & 55 & 95 & 58,64 \\
\hline TOTAL & 52 & 110 & 162 & 100 \\
\hline Porcentaje & $32,10 \%$ & $67,90 \%$ & $100 \%$ & \\
\hline
\end{tabular}

Las materias primas predominantes, después de la obsidiana verde, son principalmente la lutita $y$ la riolita. La descripción de Ortiz-Troncoso indica un predominio de lascas y desechos de talla de diversas rocas, luego lascas de obsidiana, y en orden de porcentaje mayor a menor, piedra tallada sobre masa central, piedra martillada y/o pulida (pesas de red), piedras con huellas de utilización (percutores y alisadores). Lo último en rocas variadas, y en menor frecuencia se mencionan restos de piedra tallada sobre masa central de obsidiana verde (Ortiz-Troncoso 1975:107, Fig. 10).

Los instrumentos están manufacturados en su mayoría sobre lascas, un par de casos sobre masa central y una lámina. Se trata mayoritariamente de cuchillos, y algunas raederas y bifaces. Las puntas de proyectil y bifaces se elaboran igualmente sobre lascas, como es el caso de un perforador lítico del mismo contexto. Se registra un fragmento de bifazcuchillo sobre baguette y otro instrumento sobre masa central retocada, de función indeterminada (Fig. 8).

Por otro lado, los restos líticos recuperados en el sitio PSA-2 conforman uno de los conjuntos más extraños de Patagonia, tanto por su bajísima densidad (35 artefactos contando los dudosos, sin incluir guijarros y clastos naturales) que llega a 1,4 piezas por metro cuadrado; como por la baja proporción de restos tallados en relación a artefactos de piedra piqueteada/ pulida. En los artefactos de piedra esta relación es de 1:3.

Los instrumentos registrados están dominados ampliamente por la presencia de percutores y algunos yunques, aunque estas piezas presentan poca intensidad de uso, es decir, baja incidencia de las características marcas de trituramiento (Tabla 6). Entre los instrumentos tallados y retocados 
Tabla 6. Materiales líticos de PSA-2 por categoría.

\begin{tabular}{|c|c|c|c|}
\hline CATEGORÍA & \multicolumn{3}{|c|}{ TOTAL } \\
\hline $\begin{array}{l}\text { Instrumentos } \\
\text { raedera denticulada } \\
\text { raedera, frag. }\end{array}$ & $\begin{array}{l}1 \\
2\end{array}$ & $\begin{array}{l}\mathrm{N}^{\circ} \\
3\end{array}$ & $\begin{array}{l}\% \\
5 \%\end{array}$ \\
\hline $\begin{array}{l}\text { Percutor } \\
\text { percutor dudoso } \\
\text { mano? de moler fracturada } \\
\text { sobador o mano de moler/percutor/yunque } \\
\text { yunque/percutor } \\
\text { yunque grande dudoso }\end{array}$ & $\begin{array}{l}4 \\
1 \\
1 \\
1 \\
1 \\
1\end{array}$ & 9 & $15 \%$ \\
\hline $\begin{array}{l}\text { Desechos de talla } \\
\text { Lasca } \\
\text { lasca secundaria } \\
\text { lasca interna } \\
\text { lasca de dorso natural } \\
\text { lasca dudosa }\end{array}$ & $\begin{array}{l}1 \\
4 \\
3 \\
3 \\
2\end{array}$ & 13 & $21 \%$ \\
\hline $\begin{array}{l}\text { microdesecho retoque } \\
\text { microdesecho indet. }\end{array}$ & $\begin{array}{l}1 \\
1\end{array}$ & 2 & $3 \%$ \\
\hline desecho de bola & 1 & 1 & $2 \%$ \\
\hline $\begin{array}{l}\text { desecho dudoso } \\
\text { desecho indet. }\end{array}$ & $\begin{array}{l}3 \\
1\end{array}$ & 4 & $7 \%$ \\
\hline $\begin{array}{l}\text { Otros } \\
\text { guijarro granidiorita machacado } \\
\text { arenisca plana con pulidos en ambas caras } \\
\text { arenisca con acanaladuras dudosas }\end{array}$ & $\begin{array}{l}1 \\
1 \\
1\end{array}$ & 3 & $5 \%$ \\
\hline $\begin{array}{l}\text { guijarro natural } \\
\text { guijarro natural, fract. } \\
\text { guijarro natural, frag. } \\
\text { guijarro pulido dudoso } \\
\text { roca sedimentaria natural } \\
\text { clasto natural }\end{array}$ & $\begin{array}{l}17 \\
2 \\
3 \\
2 \\
1 \\
1\end{array}$ & 26 & $43 \%$ \\
\hline TOTAL & 61 & & \\
\hline
\end{tabular}

destaca la categoría de las raederas, las que fueron manufacturadas sobre lasca, una presenta un borde con retoque marginal simple denticulado, y otra un borde con retoque discontinuo. La última pieza es solo un pequeño fragmento.

Destaca en el conjunto de instrumentos, por su morfología bien definida y las claras marcas de pulido que presentan, el caso de una piedra de moler pequeña y una mano de moler que se asemeja a un sobador, que además presenta estigmas posteriores de uso como percutor y yunque. Estos artefactos son poco comunes en el registro fueguino-patagónico (Fig. 9).

Luego, hay una serie de artefactos de piedra tallada de variadas materias primas, extraños o dudosos, con escasas piezas de claro origen antró- pico. Se registran restos de jaspe, cuarzo, RGFO de regular calidad, posiblemente dacita y una roca silícea indeterminada. Por su rareza destacan 3 lascas secundarias confeccionadas por percusión dura sobre una roca sedimentaria, guijarro tipo arenisca de color café claro. Estas lascas de tamaño mediano a grande son de adscripción cultural indudable, aunque se trata de una materia prima poco adecuada para la talla concoidal.

También hay un gran número de guijarros naturales que fueron recolectados para su revisión en el laboratorio y que no resultaron ser ningún tipo de artefacto. Tampoco es claro que hayan sido piezas transportadas al sitio ex profeso, por lo que deben considerarse simplemente como inclusiones naturales de origen sedimentario.

El sitio PSA-3 contrasta con los anteriores en tanto presenta una altísima densidad de materiales y una amplia muestra de talla lítica, lo que incluye un 93\% de núcleos y desechos de talla, indicando la importancia de la actividad. Cerca del 5\% de los artefactos corresponden a instrumentos formatizados por retoque o utilización, siendo muy abundante el conjunto de las puntas de proyectil y las preformas bifaciales $(n=36)$, las raederas $(n=25)$, los percutores $(\mathrm{n}=20)$ y el grupo de los tajadores, ya sean chopper o chopping tools. La riqueza de categorías representadas es mayor, considerando también raspadores, cuchillos, cepillos, un perforador y una pesa de red, entre otros artefactos (Tabla 7). Las puntas de proyectil son preferentemente pedunculadas, de dimensiones considerables, y muy bien logradas en su simetría y la regularidad del retoque a presión (Fig. 10).

El desbaste de núcleos $(n=88)$ está bien representado en la industria lítica de PSA-3, y los objetivos son la obtención de lascas (54,4\% del total) y láminas (2,9\%), las que están proporcionalmente reflejadas en los soportes de los instrumentos. Las cadenas operatorias de desbaste responden por $46 \%$ de los artefactos, el façonnage bifacial por un $10 \%$ y los métodos de retoque abarcan un $5 \%$ de todo el material, más un 39\% de indeterminados. La reconstrucción de la cadena operatoria de estos métodos varía, según la abundancia de la materia prima, estando el desbaste entre los métodos más abundantes y diversos, no obstante, la presencia de un $20 \%$ de desechos (lascas y láminas) de façonnage bifacial, sumado a la alta frecuencia de fragmentos de puntas de proyectil y bifaces, atestigua que la cadena 


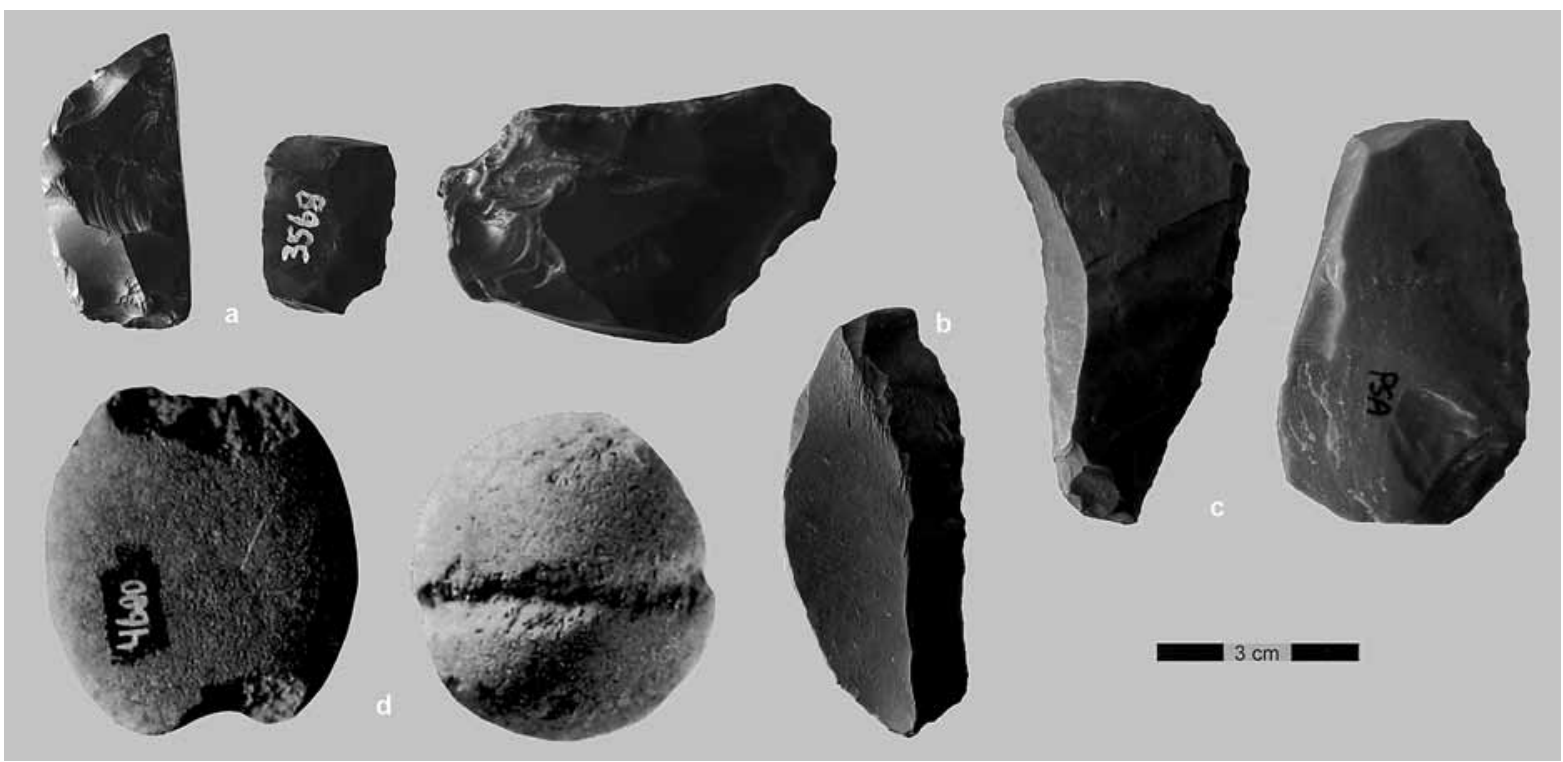

Fig. 8. Materiales líticos del sitio PSA-1: a) cuchillo, fragmento mesial de bifaz y núcleo en obsidiana verde, b) cuchillo sobre lámina en RGFO, c) cuhillo-raspador y raedera en otras materias primas y d) dos pesas de red (fotografías tomadas de Ortiz-Troncoso 1975).

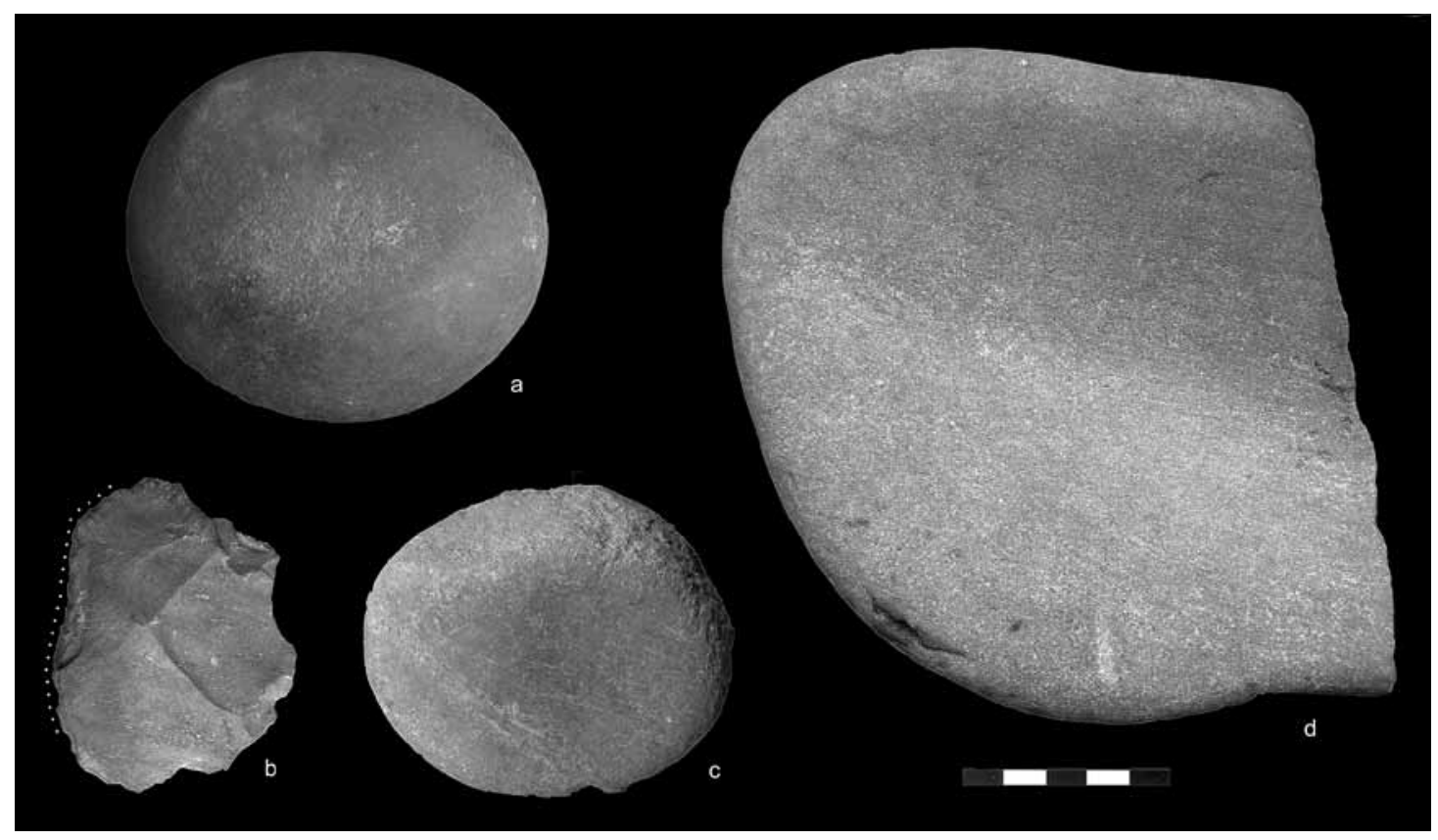

Fig. 9. Instrumentos líticos del sitio PSA-2: a) artefacto compuesto mano de moler, percutor y yunque sobre guijarro plano, b) raedera denticulada, c) mano de moler y percutor y d) piedra de moler fracturada. 
Tabla 7. Materiales líticos de PSA-3 según categorías generales y formatización.

\begin{tabular}{|lrr|}
\hline \multicolumn{1}{|c}{ CATEGORÍA } & $\mathbf{N}^{\circ}$ & $\mathbf{\%}$ \\
\hline Instrumentos y piezas formatizadas & & \\
\hline Punta de proyectil & 11 & 0,4 \\
Bifaz-preforma & 25 & 0,9 \\
Cuchillo & 8 & 0,3 \\
Raedera-cuchillo & 3 & 0,1 \\
Raedera & 25 & 0,9 \\
Raspador & 7 & 0,3 \\
Raspador-raedera & 1 & 0,0 \\
Perforador & 1 & 0,0 \\
Muesca & 2 & 0,1 \\
Limace & 1 & 0,0 \\
Cepillo & 1 & 0,0 \\
Cepillo-raedera & 5 & 0,2 \\
Chopper & 7 & 0,3 \\
Chopping tool & 10 & 0,4 \\
Pesa de red & 1 & 0,0 \\
Percutor & 20 & 0,7 \\
SUBTOTAL & 128 & 4,6 \\
Instrumentos y piezas formatizadas & & \\
\hline Núcleos y derivados & & \\
\hline Núcleo & 88 & 3,2 \\
Lasca & 1519 & 54,4 \\
Lámina & 82 & 2,9 \\
Desecho & 909 & 32,6 \\
SUBTOTAL & & \\
Núcleos y derivados & 2598 & 93,1 \\
\hline Otros restos e indeterminados & & \\
\hline Guijarro astillado & 14 & 0,5 \\
Guijarro fracturado en Split & 9 & 0,3 \\
Guijarro fracturado indet. & 24 & 0,9 \\
Clasto angular fracturado & 5 & 0,2 \\
Fragmento indet. & 12 & 0,4 \\
SUBTOTAL & 64 & 2,3 \\
Otros restos e indeterminados & $\mathbf{2 7 9 0}$ & 100,0 \\
\hline TOTAL & & \\
\hline
\end{tabular}

operatoria de manufactura de puntas de proyectil es importante en el yacimiento. Los soportes iniciales determinados son en su mayoría lascas espesas, pero no puede descartarse que algunas cadenas operatorias de façonnage bifacial comiencen con una masa central del tipo canto rodado. Luego de un rebaje inicial realizado por percusión dura, el adelgazamiento de las bifaces se realiza por percusión blanda. Es posible que se combine el uso de percutor blando mineral y orgánico, a juzgar por la presencia de huellas diagnósticas (sensu Pelegrin 2000) y el registro de varios percutores sobre guijarros de rocas sedimentarias que podrían actuar como percutor blando mineral. La etapa final, considerando las puntas de proyectil terminadas, es por retoque a presión, existiendo en algunos casos un retoque laminar muy regular.

De un total de 1353 lascas y láminas enteras o fracturadas, pero con talón, se pudo inferir el uso de percusión blanda en cerca del 16\% de los desechos de talla, aspecto que se asocia frecuentemente a la preparación del talón con abrasión y/o rebaje de aristas dorsales (17\%). Este tipo de extracciones se relaciona con la cadena de façonnage bifacial de puntas de proyectil, pero también con los métodos de desbaste de láminas.

La obtención de láminas y lascas alargadas se realiza seleccionando un soporte adecuado, ya sea un guijarro o clasto subredondeado. Se extraen láminas primarias y secundarias conformando aristas para los desprendimientos consiguientes. La preparación del talón es esmerada y en el 72\% de los casos la técnica de aplicación de la fuerza es percusión blanda (orgánica o mineral).

Por último, las materias primas seleccionadas son diversas, pero dominan las rocas sedimentarias de grano fino con un 58\% del total. Son en su mayoría de buena calidad para la talla y se identificaron al menos tres variedades. Casi todas las categorías de artefactos están representadas entre las rocas sedimentarias, y los instrumentos más frecuentes son los tajadores (chopper y chopping tools), bifaces y puntas, y entre los elementos de desbaste destaca el número de núcleos y láminas.

En PSA-3 siguen en frecuencia las rocas tipo laja o pizarra de regular a mala calidad sobre la que se manufacturaron algunas raederas. No obstante, predominan en este conjunto los desechos de talla indeterminados y hay una importante frecuencia de uso de percusión apoyada.

Otras materias utilizadas incluyen un 5,4\% de obsidiana verde, destacando una punta de proyectil pedunculada, y $4,1 \%$ de RGFO, ambas de muy buena calidad para la talla. Además se registraron distintos tipos de rocas silíceas de calidad muy buena a buena $(6,1 \%)$ y en muy baja proporción rocas como andesita, cuarcitas, esquisto, diorita, granito y otras indeterminadas. 


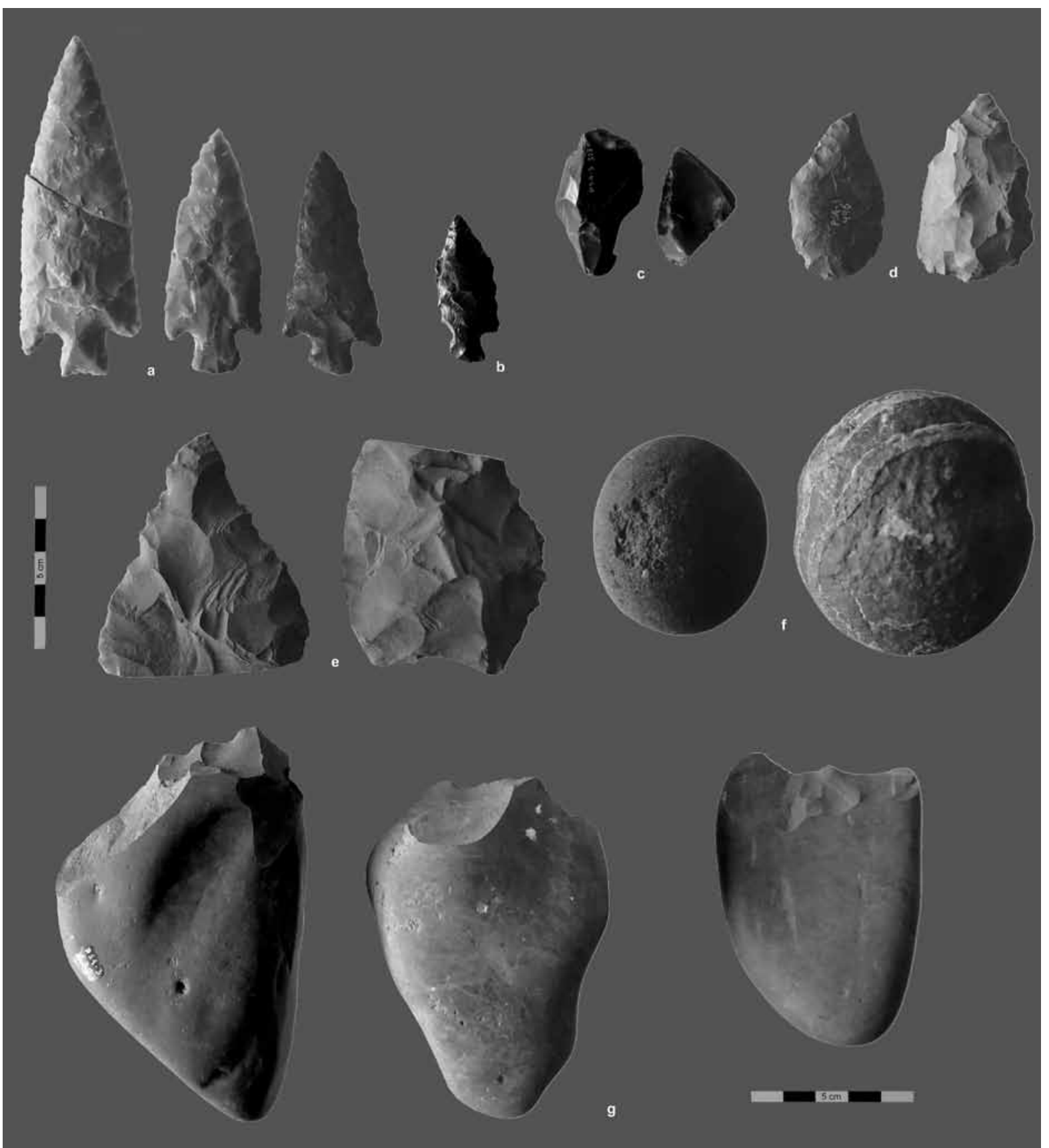

Fig. 10 Artefactos líticos de PSA-3: a) tres puntas de proyectil pedunculadas confeccionadas sobre rocas síliceas y RGFO, b) punta de proyectil pedunculada sobre obsidiana verde, c) raspador y cuchillo en obsidiana verde, d) dos puntas bifaciales sobre roca sedimentaria, e) dos fragmentos de bifaces (preformas) sobre materia prima sedimentaria, f) pequeño percutor y pesa de red sobre materias primas indeterminadas $\mathrm{y}, \mathrm{g})$ tres chopping tools sobre guijarro de roca sedimentaria. 


\section{DISCUSIÓN}

La densidad de materiales líticos, muy baja en PSA-1 y PSA-2, y alta en PSA-3, sumado a las diferencias contextuales, complejidad de los rasgos -conchales y lentes de fogón-, hacen difícil comparar estos tres yacimientos pues es posible asignarles rangos distintos de intensidad de ocupación y función inferida. Campamentos de paso en PSA-1 y PSA-2, lo que contrasta con las múltiples ocupaciones registradas en PSA-3 y la intensa actividad de talla lítica, lo que ubicaría el sitio como un nodo importante de ocupaciones reiteradas. Los fechados radiocarbónicos ubican a las ocupaciones en rangos temporales distantes entre sí y sin superposición: PSA-1 con aproximadamente 6300 años AP, PSA-2 con fechas cercanas a 2700 años y PSA-3 con un rango entre 700 y 1000 años AP.

Los principales cambios observados en las estrategias de subsistencia están dadas por la importancia de las actividades de pesca para momentos tempranos e intermedios (PSA-1 y PSA-2), actividad dominada por la captura de peces demersales (Salilota australis). Para momentos tardíos la pesca decrece y el énfasis está dado por la captura de peces de orilla, predominantemente Maclovinus eleginops y Odontesthes sp. Esta inflexión en las estrategias y/o tácticas de pesca no se explicaría por cambios ambientales, ya que desde momentos tempranos se encuentran disponibles especies de orilla en la localidad (Maclovinus eleginops), aunque el énfasis estuvo centrado en la pesca de profundidad. Para momentos tardíos podemos inferir que la disponibilidad de taxones demersales no presenta variaciones, pues estas especies continúan siendo explotadas por pescadores actuales en las inmediaciones. Estas observaciones tienen un correlato positivo en elementos de la tecnología de pesca, como son las pesas de red, cuya presencia es importante en PSA-1.

En cuanto a otros taxones, es destacable el hecho de la dominancia de procellariiformes en PSA-2, que se diferencia marcadamente del sitio temprano y tardío, caracterizados por la explotación de Phalacrocorax sp. Esta particularidad se asociaría al despliegue de técnicas de captura orientadas a especies de ámbito pelágico (fardelas) y probablemente puedan estar asociadas a los instrumentos óseos aguzados de pequeñas dimensiones, los que tal vez fueran utilizados como sistemas de captura de aves en alta mar. Esta es sólo una hipótesis que deberá ser explorada, aunque resulta interesante observar que en sitios con cronologías semejantes en el estrecho de Magallanes (KM 44, Morello et al. 2002; Offing 2 Locus 1, Legoupil et al. 2011) se presentan instrumentos similares asociados a conjuntos faunísticos con énfasis equivalentes.

Con respecto a la explotación de mamíferos, los tres conjuntos están dominados por pinnípedos, aunque en PSA-2 ocurren en baja frecuencia los restos y además, representan exclusivamente a Otaria flavescens. Resulta difícil pronunciarse sobre este hecho, aunque puede plantearse una disminución local en la disponibilidad de lobos finos, quizá relacionada con disminución de stock locales asociados al impacto antrópico generado por la instalación de los primeros cazadores marinos en el área. Sin embargo, en este contexto la predominancia de lobo común también se relaciona con la ausencia de puntas de arpón, lo que hace plausible considerar como hipótesis alternativa el rol preponderante de las elecciones tecno-económicas registradas y las estrategias cinegéticas entre los grupos humanos de tiempos intermedios en Punta Santa Ana.

En la industria sobre hueso destaca la ausencia de puntas de arma -arpones- en PSA-2. No sabemos si su ausencia se relacione a un problema de funcionalidad del sitio, a un problema de intensidad de muestreo o, simplemente, a que sus ocupantes no incluyeron dentro de su panoplia instrumental este tipo de armas asociadas a la caza de pinnípedos. En los extremos temporales se observan importantes cambios de diseño, pero principalmente asociado a aspectos morfológicos. La presencia de arpones de base cruciforme en sitios tempranos y de espaldón simple en conjuntos tardíos muestra una continuidad de principios funcionales: arpones desprendibles de los astiles que son fijados con sistemas de cuerdas o correas para retener el arma y la presa. Debemos indicar que la presencia de arpones en PSA-1 y PSA-3 estaría correlacionada al importante número de restos de pinnípedos, ocurriendo lo contrario en PSA-2.

Entre otras categorías funcionales, se observan cuñas en los sitios PSA-1 y PSA-3, aunque los tamaños y diseños muestran diferencias puntuales. La ausencia de cinceles en los sitios posteriores a PSA-1 resulta llamativa, y no estando bien identificada la actividad asociada a esta categoría morfofuncional, 
resulta difícil adelantar una explicación para este fenómeno.

Sobre la decoración de instrumentos, observamos que sólo aparece representada para momentos tempranos, aunque resulta difícil pronunciarse sobre la ausencia de dichas prácticas en los conjuntos posteriores. Esto, para el caso de PSA-2, puede relacionarse con la baja frecuencia y diversidad de instrumentos recuperados, aunque esta explicación no resultaría aceptable en el caso de PSA-3, con un conjunto claramente más importante y diversificado.

Con relación a los conjuntos de artefactos de piedra, debemos señalar que la industria lítica de PSA-1, aunque pobre, tiene la impronta cultural de la tradición Englefield, con un uso importante de obsidiana verde, la preferencia por instrumentos retocados con filos largos del tipo cuchillo y un caso de una bifaz-cuchillo sobre baguette. La presencia de pesas de red también es un distintivo de las ocupaciones de canoeros tempranos y se asocia a la importancia de las actividades de pesca, según las evidencias ictioarqueológicas discutidas previamente.

Considerando su cronología, el sitio PSA-2 se inserta en un momento temporal en la transición entre la Tradición Ponsonby (Legoupil y Pigeot 2009) y el bloque de sitios tardíos (últimos 2000 años). En su conjunto, la industria lítica de PSA-2 no se asemeja a la Tradición Ponsonby, siendo la pobreza del conjunto una de las características más notables. Lamentablemente la definición de la Tradición Ponsonby es muy limitada, en tanto se restringe a la presencia de grandes puntas lanceoladas. La única similitud sería el predominio de las raederas como categoría morfofuncional y la ausencia de obsidiana verde. En términos de otros aspectos aislados, algunos elementos recuerdan los restos del sitio Myrén 2, en Tierra del Fuego, justamente por su rareza y baja densidad, por la presencia de una raedera denticulada y por la talla de una roca sedimentaria (Prieto et al. 2007). La presencia de una piedra de moler y mano se asemeja a varias piezas registrados en el sitio Offing 2 Locus 1 que corresponde a un contexto asociado a la Tradición Ponsonby (com. pers. Dominique Legoupil). En ambos casos, los depósitos tienen antigüedades variables entre 3.900 y 2.200 años AP (Legoupil et al. 2011; Prieto et al. 2007). En especial, se destaca la contemporaneidad con las capas más recientes del sitio Offing 2 Locus 1 . Los resultados demuestran las notables diferencias del conjunto lítico de PSA2 con lo descrito para sitios de cazadores marinos tempranos, tal como en el caso de PSA-1, en donde se registra abundantes restos de piedra tallada, hay un predominio en el uso de materias primas como la obsidiana verde, y además de los instrumentos unifaciales, se observa presencia de talla bifacial, entre otros aspectos tecno-tipológicos.

En el sitio tardío PSA-3, la información es mucho más detallada y se observa gran desarrollo de las actividades de talla. La obsidiana verde vuelve a ser utilizada, y aunque sólo representa el 5\% de las rocas talladas, es una cantidad considerable de material. Las diferencias cuantitativas y cualitativas con respecto a PSA-2 son demasiadas y marcan una clara diferencia.

Al revisar otros contextos de la misma época, el sitio PSA-3 es mejor asimilado a la tradición cultural tardía. Con respecto a Pizzulic 4 (San Román 2012) y Punta Baja (Legoupil 1989), concuerdan en la presencia de contextos dominados por el façonnage bifacial y la importancia de la obsidiana verde como materia prima. Los objetivos de talla, en estos dos casos, es la confección de puntas de proyectil pedunculadas pero pequeñas, lo que marca una diferencia importante con PSA-3. Sin embargo, en el sitio Punta Baja hay dos módulos de tamaño preferente entre las puntas de proyectil, y las puntas pedunculadas de PSA-3 son muy similares en la forma del pedúnculo y aletas, además de los tamaños, en especial ancho y espesor, con las puntas de proyectil de módulo grande de Punta Baja. Aunque el promedio del largo total parece menor en las puntas de Punta Baja con relación a PSA-3.

\section{CONCLUSIONES}

El estudio realizado en la localidad de Punta Santa Ana ha permitido reconstruir una secuencia discontinua de ocupación de cazadores recolectores marinos para los últimos seis mil años. Los conjuntos estudiados corresponden a campamentos emplazados a distinta elevación sobre el nivel del mar actual, con antigüedades de 6300, 2700 y 700 años AP. Estos conjuntos habrían sido originados en lapsos cortos de tiempo y presentan una serie de características que sugieren discontinuidad en cuanto a tradiciones tecnológicas y estrategias de subsistencia a lo largo del tiempo. Sin embargo, diferencias en la intensidad de 
ocupación y la funcionalidad de los tres yacimientos investigados podrían explicar, en alguna medida, una parte de las diferencias observadas.

Las diferencias principales incluyen la predominancia de las actividades de pesca para momentos tempranos e intermedios (PSA-1 y PSA-2), aspecto relacionado con elementos tecnológicos como es la presencia de pesas de red en PSA-1. En cuanto a los taxones de aves, es destacable el hecho de la dominancia de procellariiformes en PSA-2, que se diferencia marcadamente al sitio temprano y tardío, caracterizados por la explotación de Phalacrocorax $s p$. La caza de mamíferos marinos es predominante en momentos tempranos y tardíos (PSA-1 y PSA-3), con una tecnología asociada a arpones desprendibles. En PSA-2 ocurren en baja frecuencia los restos de pinnípedos y no se registran ni arpones ni otro tipo de armas.

La industria ósea promedia diferencias notables entre las categorías presentes y su abundancia, destacando PSA-1 como el conjunto más rico y diverso. Los tipos representados, en especial los arpones, son los característicos de la tradición cultural Englefield de base cruciforme; en el bloque tardío predominan los de espaldón simple.

Igualmente, el conjunto lítico de PSA-1 tiene elementos distintivos de la tradición de los canoeros tempranos. La reducida y poco diagnóstica industria lítica de PSA-2 es difícil de relacionar con conjuntos o tradiciones tecnológicas conocidas para Patagonia, no obstante, marca un claro quiebre y discontinuidad tanto con las ocupaciones tempranas como con las posteriores.

Por último, la industria lítica de PSA-3, en comparación con otros contextos de la misma época, se integra fácilmente a la tradición cultural tardía, aspecto apoyado también por la tecnología ósea y las preferencias en el uso de materias primas líticas, especialmente la obsidiana verde.

\section{AGRADECIMIENTOS}

Esta investigación ha sido financiada en el marco del proyecto FONDECYT 1085329. Comprometen nuestra gratitud los colegas y amigos que participaron de las campañas de terreno: María José Barrientos, Pablo Calfuqueo, Catalina Contreras, Pedro Cárdenas, José Díaz, Michael Fontugne, Consuelo Huidobro, Fabiana Martin, Susana Mora- no, Omar Reyes, Carolina Rodríguez, Jimena Ruz, Mariana Saez, Kai Salas, Valentina Trejo, Rosa Tureuna y Danilo Vilicic.

\section{BIBLIOGRAFÍA}

ARROYO-KALIN, M. y C. FRENCH. 2012. Micromorphological analysis of archaeological shell middens and buried soils at Punta Santa Ana and Pizzulic-2, Magallanes, Chile. Informe Final, Proyecto FONDECYT 1085329. MS

BENTLEY, M. J. y R. D. MCCULLOCH. 2005. Impact of neotectonics on the record of glacier and sea level fluctuations, Strait of Magellan, southern Chile. Geografiska Annaler 87A(2):393-402.

LEFÈVRE, C. 1989. L'Avifaune de Patagonie Australe et ses relations avec L'Homme au cours des six derniers millenaires. Tesis de Doctorado, UER 03: Ethnologie et Préhistoire, Universidad de Paris I - Panthéon-Sorbonne, Paris. MS.

LEGOUPIL, D. 1989. Ethno-Archéologie dans les Archipels de Patagonie: les Nomades Marins de Punta Baja. Recherche sur les Civilisations 84, Paris.

1997. Bahía Colorada (Ile Englenfield). Les premiers chasseurs de mammifères marins de Patagonie australe. Recherche sur les Civilisations, Paris.

LEGOUPIL, D. Y M. FONTUGNE. 1997. El poblamiento marítimo en los archipiélagos de Patagonia: núcleos antiguos y dispersión reciente. Anales del Instituto de la Patagonia, Serie Ciencias Humanas 25:75-87.

LEGOUPIL, D. Y N. PIGEOT 2009. Les grandes pointes foliacées du type "Ponsonby ". un traceur culturel en Patagonie australe. Journal de la société des américanistes 95-2.

LEGOUPIL, D., P. BEAREZ, C. LEFÈVRE, M. SAN ROMÁN y J. TORRES. 2011. Estrategias de subsistencia de cazadores recolectores de Isla Dawson (estrecho de Magallanes) durante la segunda mitad del holoceno: primeras aproximaciones. Magallania 39(2):153-164.

MCCULLOCH, R. D. Y S. DAVIES 2001. Late-glacial and Holocene palaeoenvironmental change in the central Strait of Magellan, southern Patagonia. Palaeogeography, Palaeoclimatology, Palaeoecology 173:143-173.

MORELLO, F., M. SAN ROMÁN Y A. PRIETO 2002. Puntas de proyectil lanceoladas en Patagonia meridional y Tierra del Fuego. Anales del Instituto de la Patagonia, Serie Ciencias Humanas 30:155-166.

MORELLO, F., M. SAN ROMÁN, A. PRIETO, O. REYES, G. BAHAMONDE, J. TORRES Y M. LUCERO 2008. Línea de Base de los Recursos Culturales y Antecedentes Históricos del Área Marina Costera Protegida Francisco 
Coloane. Programa de las Naciones Unidas para el Desarrollo y Universidad de Magallanes, Punta Arenas. ORTIZ-TRONCOSO, O. 1975. Los Yacimientos de Punta Santa Ana y Bahía Buena (Patagonia Austral). Excavaciones y Fechados Radiocarbónicos. Anales del Instituto de la Patagonia 7:93-122.

1977-78. Nuevas dataciones radiocarbónicas para Chile Austral (Patagonia y Tierra del Fuego). Boletín del Museo Arqueológico de La Serena 16:244-250.

1979. Punta Santa Ana et Bahía Buena: deux Gisements sur une ancienne ligne de rivage dans le détroit de Magellan. Journal de la Société des Américanistes 60(6):133-204.

PELEGRIN, J. 2000. Les techniques de debitage laminaire au Tardiglaciaire: critères de diagnose et quelques réflections. Mémoires du Musée de Prehistoire d'Ile de France 7: 73-79.

PIANA, E., M. VELAZQUEZ y A. M. TIVOLI. 2007. Dieta y algo más. Animales pequeños y variabilidad del comportamiento humano en el canal Beagle. En : Arqueología de Fuego-Patagonia. Levantando piedras, desenterrando huesos... y develando arcanos. Editado por F. Morello, M. Martinic, A. Prieto y G. Bahamonde. Ediciones CEQUA, Punta Arenas.

PRIETO, A., E. CALÁS, F. MORELLO y J. TORRES 2007. El sitio arqueológico Myren 2, Tierra del Fuego, Chile. Magallania 35(2):89-103.

PORTER, S., M. STUIVER y C. J. HEUSSER. 1984. Holocene Sea-Level Changes along the Strait of Magellan and Beagle Channel, Southern South America. Quaternary Research 22:59-67.

SAN ROMÁN, M. 2010. La explotación de recursos faunísticos en el sitio Punta Santa Ana 1: estrategias de subsistencia de grupos de cazadores marinos tempranos de Patagonia meridional. Magallania 38(1):183-198.

2012. Sitios arqueológicos de isla Englefield, mar de Otway: nuevas evidencias de discontinuidad cultural en el proceso de poblamiento marítimo de Patagonia meridional. Poster presentado en VIII Jornadas de Arqueología de la Patagonia. 3 al 7 de octubre de 2011, Malargüe, Argentina. En evaluación.

SAN ROMÁN, M; K. SALAS Y M. FONTUGNE 2009. Primeros avances en la reconstrucción de secuencias de ocupación de cazadores recolectores marinos en el estrecho de Magallanes, Patagonia meridional. En: Arqueología de la Patagonia. Una Mirada desde el último confín, compilado por Mónica Salemme, Fernando Santiago, Myrian Álvarez, Ernesto Piana, Martín Vázquez y María Estela Mansur, pp. 35-43. Editorial Utopías, Ushuaia.

SCHIDLOWSKY, V. 1999. Comportements techno-économiques et identité culturelle des premiers chasseurs maritimes et des chasseurs terrestres de Patagonie Australe. Tesis de Doctorado, Paris-I Panthéon-Sorbonne. MS.

SOTO-HEIN, P. 1992. Le peuplement Paléo-Indien et archaique d'Amérique du sud. Étude anthropologique et analyse comparative avec le peuplement sub-actuel. Tesis de Doctorado, Museum National d'Histoire Naturelle (A L'Institut de Paléontologie Humaine). MS.

TOBAR, D., S. TOBAR, D. RUIZ Y G. RUIZ. 2008. Vida Militar en Magallanes 1900-1950. Ejército de Chile y Universidad de Magallanes, Punta Arenas.

TORRES, J. y J. RUZ. 2011. Pescadores de la Tradición Cultural Englefield. Datos preliminares en la zona del estrecho de Magallanes y mar de Otway XII Región de Magallanes, Chile. Magallania 39(2) 
